\title{
DISORGANIZATION OF LANGUAGE AND WORKING MEMORY SYSTEMS IN FRONTAL VERSUS TEMPORAL LOBE EPILEPSY
}

\author{
Lorenzo Caciagli,,${ }^{1,2,3}$ Casey Paquola,${ }^{4}$ Xiaosong He, ${ }^{1}$ Christian Vollmar, ${ }^{2,3,5}$ Maria \\ Centeno, ${ }^{2,3,6}$ Britta Wandschneider, ${ }^{2,3}$ Urs Braun, ${ }^{1,7}$ Karin Trimmel, ${ }^{2,3,8}$ Sjoerd B. Vos, $, 2,3,10$ \\ Meneka K. Sidhu, ${ }^{2,3}$ Pamela J. Thompson, ${ }^{2,3}$ Sallie Baxendale, ${ }^{2,3}$ Gavin P. Winston, ${ }^{2,3,11}$ John \\ S. Duncan, ${ }^{2,3}$ Danielle S. Bassett, $* 1,12,13,14,15,16$ Matthias J. Koepp, ${ }^{* 2,3}$ and Boris C. \\ Bernhardt*4 \\ * denotes equal contribution as senior author \\ ${ }^{1}$ Department of Bioengineering, University of Pennsylvania, Philadelphia, Pennsylvania 19104 USA \\ ${ }^{2}$ Department of Clinical and Experimental Epilepsy, UCL Queen Square Institute of Neurology, \\ London WC1N 3BG, United Kingdom \\ ${ }^{3}$ MRI Unit, Epilepsy Society, Chalfont St Peter, Buckinghamshire, SL9 ORJ United Kingdom \\ ${ }^{4}$ Multimodal Imaging and Connectome Analysis Laboratory, McConnell Brain Imaging Centre, \\ Montreal Neurological Institute, Quebec H3A 2B4 Canada \\ ${ }^{5}$ Department of Neurology, Ludwig-Maximilians-Universität, Marchioninistrasse 15, 81377 Munich, \\ Germany \\ ${ }^{6}$ Epilepsy Unit, Hospital Clínic de Barcelona, Carrer de Villaroel 170, 08036 Barcelona, Spain \\ ${ }^{7}$ Department of Psychiatry and Psychotherapy, Central Institute of Mental Health, Medical Faculty \\ Mannheim, University of Heidelberg, Mannheim \\ ${ }^{8}$ Department of Neurology, Medical University of Vienna, Vienna, Austria \\ ${ }^{9}$ Centre for Medical Image Computing, University College London, London, United Kingdom \\ ${ }^{10}$ Neuroradiological Academic Unit, UCL Queen Square Institute of Neurology, University College \\ London, London, UK \\ ${ }^{11}$ Department of Medicine, Division of Neurology, Queen's University, Kingston, Ontario, Canada \\ ${ }^{12}$ Department of Physics and Astronomy, University of Pennsylvania, Philadelphia, Pennsylvania \\ 19104 USA \\ ${ }^{13}$ Department of Electrical and Systems Engineering, University of Pennsylvania, Philadelphia, \\ Pennsylvania 19104 USA \\ ${ }^{14}$ Department of Neurology, University of Pennsylvania, Philadelphia, Pennsylvania 19104 USA \\ ${ }^{15}$ Department of Psychiatry, University of Pennsylvania, Philadelphia, Pennsylvania 19104 USA \\ ${ }^{16}$ Santa Fe Institute, Santa Fe, New Mexico 87501 USA
}

Running title: Mapping cognitive dysfunction in FLE and TLE

294 words in abstract, 5994 words in document body, 6 Figures, 2 Tables.

6 Supplementary Figures, 8 Supplementary Tables.

\section{Correspondence to the below authors:}

Lorenzo Caciagli, $M D, P h D$

Department of Bioengineering, University of Pennsylvania

240 Skirkanich Hall, 210 South $33^{\text {rd }}$ Street, Philadelphia, PA 19104, USA

NOTE: This preprint reports new research that has not been certified by peer review and should not be used to guide clinical practice. 
medRxiv preprint doi: https://doi.org/10.1101/2021.02.19.21251501; this version posted February 23, 2021. The copyright holder for this preprint (which was not certified by peer review) is the author/funder, who has granted medRxiv a license to display the preprint in It is made available under a CC-BY-NC-ND 4.0 International license

Email address: lcaciagl@seas.upenn.edu; lorenzo.caciagli.11@ucl.ac.uk

Danielle S. Bassett, PhD

Department of Bioengineering, University of Pennsylvania

240 Skirkanich Hall, 210 South $33^{\text {rd }}$ Street, Philadelphia, PA 19104, USA

Email address: dsb@seas.upenn.edu

Matthias J. Koepp, $M D, P h D$

Department of Clinical and Experimental Epilepsy, UCL Queen Square Institute of Neurology

33 Queen Square, Box 29, London WC1N 3BG, United Kingdom

Email address: m.koepp@ucl.ac.uk

Boris C. Bernhardt, PhD

McConnell Brain Imaging Center, Montreal Neurological institute and Hospital

3801 Rue University, Montreal, Quebec H3A 2B4, Canada

Email address: boris.bernhardt@mcgill.ca 
medRxiv preprint doi: https://doi.org/10.1101/2021.02.19.21251501; this version posted February $23,2021$. The copyright holder for this preprint (which was not certified by peer review) is the author/funder, who has granted medRxiv a license to display the preprint in

It is made available under a CC-BY-NC-ND 4.0 International license

\begin{abstract}
Cognitive impairment is a common comorbidity of epilepsy, and adversely impacts people with both frontal lobe epilepsy (FLE) and temporal lobe epilepsy (TLE). While the underlying neural substrates in TLE have been extensively investigated, functional imaging studies in FLE are scarce. In this study, we profiled cognitive dysfunction in FLE, and directly compared FLE and TLE patients to establish commonalities and differences. We investigated 172 adult participants (56 with FLE, 64 with TLE, and 52 controls), using neuropsychological tests and four functional MRI tasks probing the neural correlates of expressive language (verbal fluency, verb generation) and working memory (verbal and visuo-spatial). Patient groups were comparable in disease duration and anti-epileptic drug load. We devised a multiscale approach to map the landscape of brain activation and deactivation during cognition, and track reorganization in FLE and TLE. Voxel-based analyses were complemented with profiling of task effects (i) across intrinsic functional systems, and (ii) along the principal functional connectivity gradient, which encodes a continuous transition from lower-level sensory to higher-order transmodal brain areas. We show that cognitive impairment in FLE is associated with reduced activation across attentional and executive systems, and reduced deactivation of the default mode system, indicative of a large-scale disorganization of task-related recruitment. Functional abnormalities in FLE were modulated by disease load. Patterns of dysfunction in FLE were broadly similar to those in TLE, but some traits were syndrome-specific: altered default-mode deactivation was more prominent in FLE, while impaired recruitment of posterior language areas during a task with semantic demands was more marked in TLE. Our study elucidates neural processes underlying language and working memory impairment in FLE, identifies shared and syndrome-specific alterations in the two most common focal epilepsies, and sheds light on system behavior that may be amenable to future remediation strategies.
\end{abstract}


medRxiv preprint doi: https://doi.org/10.1101/2021.02.19.21251501; this version posted February 23, 2021. The copyright holder for this preprint (which was not certified by peer review) is the author/funder, who has granted medRxiv a license to display the preprint in It is made available under a CC-BY-NC-ND 4.0 International license

\section{KEYWORDS}

Frontal lobe epilepsy; temporal lobe epilepsy; cognition; fMRI; multiscale functional mapping.

\section{ABBREVIATIONS}

ASM: anti-seizure medication; DMN: default-mode network; FCD: focal cortical dysplasia; FDA: functional data analysis; FDR: false discovery rate; FLE: frontal lobe epilepsy; fMRI: functional magnetic resonance imaging; FSL: FMRIB Software Library; FWE: familywise error (rate); FWHM: full width at half-maximum; HCP: Human Connectome Project; LI: laterality index; MNI: Montreal Neurological Institute; NHNN: National Hospital for Neurology and Neurosurgery; ROI: region of interest; S(n)PM: Statistical (non-) Parametric Mapping; TLE: temporal lobe epilepsy. 
medRxiv preprint doi: https://doi.org/10.1101/2021.02.19.21251501; this version posted February 23, 2021. The copyright holder for this preprint (which was not certified by peer review) is the author/funder, who has granted medRxiv a license to display the preprint in

It is made available under a CC-BY-NC-ND 4.0 International license .

\section{INTRODUCTION}

Frontal lobe epilepsy (FLE), the second most common focal epilepsy syndrome after temporal lobe epilepsy (TLE), is frequently drug-resistant and MRI-negative. ${ }^{1-3}$ Cognitive dysfunction is common in both FLE and TLE, and adversely impacts quality of life and psychosocial functioning. ${ }^{4}$ Impaired episodic memory and semantic knowledge are common in TLE, though dysexecutive traits frequently coexist. ${ }^{5-7}$ In contrast, FLE has a less established cognitive signature. Multiple domains may be affected, including dexterity, attention, working memory, verbal fluency, executive functions, and episodic memory. ${ }^{8-12}$ Whether cognitive profiles in FLE and TLE may be distinct remains controversial, and several investigations concluded that these syndromes cannot be discriminated on cognitive measures. ${ }^{9,13,14}$ It is however suggested that episodic memory impairment is more profound in TLE, while executive functions may be more affected in FLE. ${ }^{8,15-17}$

Task-based functional MRI (fMRI) probes the neural correlates of cognitive dysfunction in epilepsy. In TLE, altered activation and connectivity of parietal and mesiotemporal areas underlie working memory impairment, ${ }^{18,19}$ while language fMRI studies indicate altered fronto-temporal activation and connectivity, with complex intra- and inter-hemispheric reorganization. ${ }^{20-26}$ In contrast, only few studies ${ }^{27}$ investigated FLE. Pediatric FLE patients had reduced fronto-temporo-parietal connectivity on a working memory fMRI task, but no substantial alteration in regional activation. ${ }^{28}$ Previously, we reported enhanced frontotemporal activation during episodic memory encoding in adult FLE patients, along with reduced mesiotemporal activation in those with poorer memory. ${ }^{29}$ Abnormal activity of motor and posterior parietal cortices during a motor coordination task may underlie impaired dexterity. ${ }^{30}$ Overall, a comprehensive overview of the neural substrates of cognitive dysfunction in FLE is lacking.

Here, we aimed to characterize the functional neuroanatomy of expressive language and working memory, cognitive functions reliant on frontal lobe processing, ${ }^{31,32}$ in individuals with drug-resistant FLE who underwent neuropsychological tests and four fMRI tasks. We compared patients with FLE to (i) healthy controls, and to (ii) a "patient control group" of individuals with TLE, comparable for epilepsy duration and anti-seizure medication (ASM) load, which allowed establishing shared and syndrome-specific traits.

We devised a multiscale functional mapping scheme to investigate the landscape of competing brain activation and deactivation during cognition, ${ }^{33-35}$ and capture disease-related 
medRxiv preprint doi: https://doi.org/10.1101/2021.02.19.21251501; this version posted February 23, 2021. The copyright holder for this preprint (which was not certified by peer review) is the author/funder, who has granted medRxiv a license to display the preprint in It is made available under a CC-BY-NC-ND 4.0 International license .

reorganization. We complemented traditional voxel-based activation analyses by profiling task effects (i) across established cognitive systems, ${ }^{36}$ and (ii) in relation to the principal gradient of intrinsic functional connectivity. ${ }^{37,38}$ The gradient describes a continuous transition of neural function, with unimodal sensory areas at one end, and high-order transmodal regions at the opposite end. As such, it recapitulates established models of cortical hierarchy, ${ }^{39}$ and offers a formal framework to characterize organizational aspects of cognitive activity, as exemplified by recent work in healthy adults ${ }^{40-42}$ and people with TLE engaged in a pattern separation task. ${ }^{43}$ By conveying regional, systems-level and global viewpoints on the neural signatures of cognitive dysfunction in epilepsy, our innovative approach proves sensitive to both localized and higher-order abnormalities.

We anticipated expressive language and working memory impairment in FLE. We hypothesized that such impairment would be underpinned by (i) reduced activation of areas engaged during task execution, i.e., "task-positive" regions, (ii) reduced deactivation of default-mode areas (DMN), i.e., "task-negative" regions, and (iii) global disorganization of cognitive network recruitment, as quantified via gradient analysis. We also hypothesized that, based on the proximity to the epileptic focus, (i) frontal and systems-level working memory abnormalities may be more prominent in FLE than TLE, (ii) language-related activation of frontal areas would be worse in FLE, and (iii) engagement of temporal language areas would be worse in TLE. We also aimed to corroborate the neurobehavioral validity of our fMRI tasks by correlating imaging patterns with neuropsychological and task performance measures. Finally, we explored associations between cognitive network alterations and clinical characteristics considered as measures of disease load, such as age at onset and epilepsy duration, and replicated our main FLE findings in a more homogeneous patient subgroup with frontal cortical dysplasia. 
medRxiv preprint doi: https://doi.org/10.1101/2021.02.19.21251501; this version posted February 23,2021 . The copyright holder for this preprint (which was not certified by peer review) is the author/funder, who has granted medRxiv a license to display the preprint in It is made available under a CC-BY-NC-ND 4.0 International license .

\section{MATERIALS AND METHODS}

\section{Participants}

This study investigated 172 participants recruited from 2007 to 2013: 120 drug-resistant patients under surgical consideration, of whom 56 had drug-resistant FLE (29 female; 30/26 left-/right-sided FLE) and 64 had drug-resistant TLE (44 female; 34/30 left-/right-sided TLE), and 52 healthy controls (32 female) with no family history of epilepsy and no neurological or psychiatric diagnosis. Demographic and clinical characteristics are provided in Table 1; further details are available in the Supplementary Methods. Written informed consent was obtained from all participants according to the standards of the Declaration of Helsinki. Participant recruitment was approved by the University College London Institute of Neurology and University College London Hospitals Research Ethics Committee. Exclusion criteria were nonproficiency in written and spoken English, MRI contraindications, pregnancy, and inability to give informed consent.

Groups were comparable for handedness and (binary) sex, but not for age, which was used as a covariate in all group analyses. Patient groups did not differ in age at onset and duration of epilepsy, number of ASMs, and usage of levetiracetam or topiramate/zonisamide, which more favorably or unfavorably influence cognitive network activity compared to other common ASMs, respectively. ${ }^{44,45}$ FLE was heterogeneous in terms of etiology and MRI findings (Table 1, Supplementary Material). We thus conducted sensitivity analyses on a subgroup with a more homogeneous etiology (focal cortical dysplasia; FLE-FCD, n=13). Moreover, we separately studied left and right FLE subgroups.

\section{Neuropsychological data}

Participants underwent standardized neuropsychological tests ${ }^{46}$ providing measures of general intellectual level (IQ), working memory, letter and category fluency, naming, psychomotor speed and executive function (mental flexibility), verbal and visuo-spatial learning and recall. Verbal reasoning and comprehension scores were available for patient groups. Test details are provided in the Supplementary Methods.

\section{Imaging data acquisition and fMRI tasks}

All imaging data were acquired on the same GE Signa HDx 3T MRI scanner at the Epilepsy Society MRI Unit, Chalfont St Peter, Buckinghamshire. Data acquisition is described in the 
medRxiv preprint doi: https://doi.org/10.1101/2021.02.19.21251501; this version posted February 23,2021 . The copyright holder for this preprint (which was not certified by peer review) is the author/funder, who has granted medRxiv a license to display the preprint in It is made available under a CC-BY-NC-ND 4.0 International license

Supplementary Methods. One visuo-spatial and one verbal fMRI paradigm assessed working memory. During the visuo-spatial (Dot Back) task, dots appeared in four possible locations on a screen. Participants were instructed to move a joystick to the position of the currently presented dot (0Back), or to the position of the dot displayed one (1Back) or two presentations earlier (2Back). ${ }^{47}$ There were five 30 s blocks for each condition in pseudo-random order, intermixed with $15 \mathrm{~s}$ of cross-hair fixation. During the verbal working memory task, single concrete nouns were displayed every $3 \mathrm{~s}$ within 30 s blocks. Participants responded upon display of a given control word (active control condition), or upon recurrence of a word displayed two presentations earlier (2Back working memory). There were five 30s blocks per condition, intermixed with $15 \mathrm{~s}$ of cross-hair fixation. Two tasks probed expressive language. During verbal fluency fMRI, participants covertly generated words beginning with a visuallypresented letter (A/D/E/S/W; one letter per block, five 30s blocks), alternating with 30s blocks of cross-hair fixation. ${ }^{48}$ During the verb generation task, subjects covertly generated verbs associated with a visually-displayed noun ("Generate"), or subvocally repeated a visuallydisplayed noun ("Repeat"). There were four 30s blocks per condition and four cross-hair fixation blocks. ${ }^{49}$

\section{Statistical analysis of clinical and neuropsychological data}

Data were analyzed using $R-3.6 .1$ and SPSS-27. For demographics, we used Fisher's exact test, one-way ANOVA and Kruskal-Wallis tests for categorical, continuous parametric and nonparametric variables, respectively. Neuropsychological data were compared via ANCOVA, covarying for age and sex. Comparisons against published norms were attained with one sample $t$-tests (details in the Supplementary Methods). Working memory task performance measures were not normally distributed, and were compared via Kruskal-Wallis tests. Across cognitive domains, we corrected for multiple comparisons via the false discovery rate (FDR) procedure. ${ }^{50}$ Post-hoc tests were Bonferroni-corrected.

\section{Functional MRI data: pre-processing and voxel-based statistics}

Functional imaging data were analyzed with SPM12 (http://http://www.fil.ion.ucl.ac.uk/spm/). Preprocessing included realignment, normalization to a scanner- and acquisition-specific echoplanar imaging template in Montreal Neurological Institute (MNI) space, resampling to $3 \times 3 \times 3 \mathrm{~mm}$ isotropic voxels, and smoothing with a Gaussian kernel of $8 \times 8 \times 8 \mathrm{~mm}$ full-width at half-maximum. ${ }^{51}$ Individual-level condition-specific effects were derived via general linear models. Task conditions were modelled as 30s blocks and convolved with the canonical 
medRxiv preprint doi: https://doi.org/10.1101/2021.02.19.21251501; this version posted February 23,2021 . The copyright holder for this preprint (which was not certified by peer review) is the author/funder, who has granted medRxiv a license to display the preprint in

It is made available under a CC-BY-NC-ND 4.0 International license .

hemodynamic response function. For verbal fluency fMRI, we created activation contrasts associated with generating words. For verb generation fMRI, we subtracted word repetition from word generation. For verbal working memory fMRI, we subtracted verbal monitoring from the 2Back working memory condition. For visuo-spatial working memory fMRI, we contrasted the condition with low working memory demand against the active control condition (1-0Back), and directly compared activation for high and low working memory demand (21Back). Voxel-wise contrast estimates ( $\beta$ weights) were computed with six motion parameters as confound regressors. Scans with a mean framewise displacement $>0.5 \mathrm{~mm}$ were discarded from further analysis. ${ }^{52}$ Additional quality checks and final participant numbers are provided in the Supplementary Methods.

Group analyses were conducted with nonparametric permutation tests, using SnPM13 ${ }^{53}$ (http://www.nisox.org/Software/SnPM13/). One-sample permutation $t$-tests assessed effects of each task condition per group. Following exploratory permutation-based $F$-tests, group differences were assessed via two-sample permutation $t$-tests, all with 10000 permutations. Statistical significance was set at two-tailed $\mathrm{p}<0.05$, voxel-wise corrected for familywise-error rate (FWE) ${ }^{54}$ within pre-specified language, working memory and DMN ("task-negative") regions of interests (ROIs; Supplementary Fig. 1). All comparisons included age and sex as covariates; comparisons of FLE versus TLE included side of the epileptic focus as additional covariate. Further details regarding group comparisons are outlined in Table 2. ROI definition is discussed in the Supplementary Methods.

\section{Functional MRI data: effects on canonical systems and principal gradient}

Voxel-based analyses elucidate task effects and group differences at a regional level. Pursuant to a higher-order, ensemble view on cognition-related brain activity, we quantified task- effects across seven intrinsic functional systems ${ }^{36}$ (Figure 1): visual, somatomotor, dorsal attention, salience (or ventral attention), (para)limbic, cognitive control (frontoparietal), and DMN. For each task contrast, we extracted $\beta$ weights from all parcels of the Schaefer brain atlas ${ }^{55}$ (200 ROI scale, MNI space) via FSL-6.0.2, averaged $\beta$ weights across ROIs belonging to a given system, and adjusted the latter for age and sex. Profiling of task effects along the principal functional gradient was conducted in surface space ${ }^{37,56}$ (Supplementary Methods). The gradient was computed from resting-state fMRI data of 100 Human Connectome Project (HCP) participants via non-linear dimensionality reduction of surface-registered functional connectivity metrics. ${ }^{57,58} \mathrm{HCP}$ acquisition and preprocessing have been detailed elsewhere. ${ }^{59}$ 
medRxiv preprint doi: https://doi.org/10.1101/2021.02.19.21251501; this version posted February 23,2021 . The copyright holder for this preprint (which was not certified by peer review) is the author/funder, who has granted medRxiv a license to display the preprint in It is made available under a CC-BY-NC-ND 4.0 International license

The gradient was discretized into 20 equally-sized bins, as previousy; ${ }^{40,56}$ cortical locations were assigned to each bin, with mainly sensory or motor regions assigned to the $1^{\text {st }}$ bin, and transmodal regions assigned to the $20^{\text {th }}$ bin. For each participant and task contrast, we derived average $\beta$ weights in each bin via a sliding window approach, ${ }^{60}$ and adjusted them for age and sex.

\section{Functional MRI data: statistics for system and gradient analyses}

In controls, one-sample permutation $t$-tests assessed task effects per system or gradient bin. We computed deviation $(\mathrm{Z})$ scores to determine the atypicality of effects in patients $\left[\mathrm{Z}_{p a t}=\left(\mathrm{Act}_{\text {pat }}\right.\right.$ $\left.\left.-\mu_{C T R}\right) / \sigma_{C T R}\right]$, where $\mu_{C T R}$ and $\sigma_{C T R}$ correspond to the mean and standard deviation of systemslevel or bin-wise $\beta$ weight in controls for a given task contrast. ${ }^{61,62}$ For each system or gradient bin, Z-score deviations from zero in patients were assessed with two-tailed, permutation-based one-sample $t$-tests. FLE and TLE were compared via permutation-based two-tailed two-sample $t$-tests. For gradient analyses, group comparisons also assessed global differences between curves of gradient-stratified task effects (areas between curves; AbC), using a nonparametric permutation test based on functional data analysis techniques ${ }^{63}$ (FDA; Supplementary Methods). We used 10000 permutations for all tests, and report Cohen's $d$ effect sizes. $P$-values were FDR-adjusted for number of systems or gradient bins; comparisons reaching uncorrected $p<0.05$ ( $p_{\text {unc }}$ ) and related effect sizes are reported for completeness. Group comparisons constrained to the left-hemispheric sections of the seven systems are also reported for language tasks, given the predominant left lateralization of language processing. Follow-up analyses of effects across DMN and cognitive control system subdivisions, derived from a more finegrained 17-system parcellation, ${ }^{36}$ are shown in the Supplementary Results.

\section{Correlation of functional MRI data with cognitive performance and clinical variables}

Across scales, we assessed correlations of task effects with cognitive performance in all participants ${ }^{22,43}$ using permutation-based analyses, each entailing 10000 permutations. Voxelbased regressions were conducted with SnPM13; age, sex and group were nuisance covariates. Associations between cognitive scores and fMRI metrics were explored within language, working memory and task-negative ROIs (Table 2). Effects are reported at two-tailed, voxelwise $p_{\mathrm{FWE}}<0.05$, unless otherwise stated. For correlations between task effects across systems or on the gradient, parameterized as age- and sex-adjusted $\beta$ weights, and cognitive 
medRxiv preprint doi: https://doi.org/10.1101/2021.02.19.21251501; this version posted February 23, 2021. The copyright holder for this preprint (which was not certified by peer review) is the author/funder, who has granted medRxiv a license to display the preprint in It is made available under a CC-BY-NC-ND 4.0 International license.

performance measures, we employed permutation-based two-tailed product-moment correlations. For verbal and visual working memory task performance measures, which were skewed, we employed permuted rank correlations with 10000 permutations. Correlations between fMRI activation and clinical variables, such as age at onset and disease duration, ${ }^{22}$ were separately computed in FLE and TLE, to disentangle syndrome-specific effects. In SnPM13, voxel-based regressions used sex and side of seizure focus as covariates. Statistical significance was established using the same ROIs as above. For correlations between clinical variables and task effects across systems or gradient, we used two-tailed, permutation-based product-moment correlations.

\section{Data availability}

Data supporting the findings of this study are available from the corresponding authors upon reasonable request.

Analytic code will be available at https://github.com/lcaciagl/Language_WM_FLE_vs_TLE upon manuscript acceptance for publication. 
medRxiv preprint doi: https://doi.org/10.1101/2021.02.19.21251501; this version posted February 23,2021 . The copyright holder for this preprint (which was not certified by peer review) is the author/funder, who has granted medRxiv a license to display the preprint in

It is made available under a CC-BY-NC-ND 4.0 International license .

\section{RESULTS}

\section{Neuropsychological data and fMRI task performance}

Patients with FLE differed from controls and/or published norms for most cognitive measures (all $p$ FDR $<0.001$; Table 1). Compared to patients with TLE, those with FLE scored higher on naming, verbal learning, and verbal recall tests, and lower on a mental flexibility test (post-hoc $\mathrm{p}<0.05$, Bonferroni-corrected). Working memory, letter and category fluency were equally impaired in FLE and TLE. Patients with FLE performed the verbal working memory task less well than controls, but similarly to those with TLE (>80\% median accuracy in both patient groups). For visual working memory, performance in FLE was worse than controls during both task conditions, with more marked effects for higher task difficulty; there were no differences between FLE and TLE.

\section{Cognitive fMRI: synopsis}

During language tasks, we found reduced activation of frontal areas and reduced deactivation of DMN nodes in FLE compared to controls. Abnormalities during working memory in FLE included reduced frontoparietal activation, reduced DMN deactivation, and global disorganization of task-related recruitment. For visual working memory, we observed a combination of (i) increased frontoparietal activation and lesser DMN deactivation than controls for low-level task demands, followed by (ii) reduced frontoparietal activation for higher task demands. Patterns of dysfunction in FLE broadly overlapped with those observed in TLE; DMN abnormalities, however, more evident in FLE, while reduced activation of posterior language areas was more marked in TLE.

The following sections present these findings in detail. For voxel-based analyses, the figures show regionally unconstrained whole-brain maps, and outline corrected as well as uncorrected findings for completeness, and in accord with benchmark evidence. ${ }^{64}$ As detailed above, however, voxel-based statistical tests focused on effects in prespecified cortical regions, and we only discuss findings that survive voxel-wise FWE-correction for multiple comparisons.

\section{Verbal fluency fMRI}

In controls, the verbal fluency task activated fronto-temporo-parietal cortices, along with hippocampus and subcortical regions (Figure 1); deactivation encompassed DMN areas, including medial prefrontal, medial parietal and angular cortices. Analysis of systems provided 
medRxiv preprint doi: https://doi.org/10.1101/2021.02.19.21251501; this version posted February 23,2021 . The copyright holder for this preprint (which was not certified by peer review) is the author/funder, who has granted medRxiv a license to display the preprint in It is made available under a CC-BY-NC-ND 4.0 International license

an ensemble perspective on these findings, showing activation of cognitive control and salience systems $\left(\beta=0.10 / 0.08, p_{\mathrm{FDR}}=0.004 / 0.020\right)$, and tendencies for deactivation of the whole DMN at uncorrected thresholds $\left(\beta=-0.06, p_{\text {unc }}=0.038\right.$; see Supplementary Results for analyses across DMN subsystems). Gradient-based profiling sorted cortical regions according to a sensory-totransmodal hierarchy, and showed: (i) positive task effects at the unimodal gradient end, reflecting activation of visual/primary sensory areas; (ii) positive effects along intermediate and right-sided segments, supporting the engagement of attentional (perceptually-coupled) and high-order executive processing; and (iii) a negative deflection at the transmodal gradient apex, capturing default-mode deactivation (all $\left.p_{\mathrm{FDR}}<0.05\right)$.

Compared to controls (Figure 2, Supplementary Table 1), FLE patients had reduced activation of left middle and inferior frontal gyrus, middle-anterior and middle-posterior temporal areas, $\left(p_{\mathrm{FWE}}<0.05\right)$, and reduced deactivation of bilateral anterior and posterior DMN, left posterior temporal and angular gyrus $\left(p_{\mathrm{FWE}}<0.05\right)$. FLE patients had similar cortical activation to the TLE group, but lesser deactivation of posterior temporal and anterior DMN areas $\left(p_{\mathrm{FWE}}<0.05\right)$. Analysis of systems identified lower left-hemispheric cognitive control and limbic activity in FLE than controls $\left(p_{\text {unc }}=0.037 / 0.010 ; d=-0.30 /-0.36\right.$ ), but no differences across whole-brain systems. DMN and cognitive control subdivisions undergoing deactivation in healthy controls showed lesser deactivation in FLE (DMN-A/DMN-C/control-C: $p_{\mathrm{FDR}}=0.004 / 0.0025 /<0.001$, $d=0.51 / 0.39 / 0.65$; Supplementary Results, Supplementary Fig. 3). Curves of gradient-based task effects showed localized differences between FLE patients and controls, including (i) weaker task activity in intermediate gradient segments, and (ii) an increase at the transmodal apex, which implies lesser deactivation (all $p_{\mathrm{FDR}}<0.05$ across bins; $d=-0.39$ to -0.42 for intermediate bins, $d=0.54$ to 0.64 for bins at the apex). There were no differences between FLE and TLE for analyses of systems and gradients.

\section{Verb generation fMRI}

In controls, the verb generation task activated fronto-temporo-parietal cortices and subcortical areas (Figure 1). Lateral temporal effects were more marked than in verbal fluency; moreover, the left posterior temporal cortex and angular gyrus belonged to the task activation map. Task activation involved cognitive control, DMN, salience and dorsal attention systems $\left(\beta=0.12 / 0.06 / 0.08 / 0.06, p_{\mathrm{FDR}}<0.0001 / 0.017 / 0.0001 / 0.017\right.$, respectively). Gradient profiles indicated extensive activation across the intermediate-to-transmodal gradient segments (all $\left.p_{\text {FDR }}<0.05\right)$. 
medRxiv preprint doi: https://doi.org/10.1101/2021.02.19.21251501; this version posted February 23,2021 . The copyright holder for this preprint (which was not certified by peer review) is the author/funder, who has granted medRxiv a license to display the preprint in It is made available under a CC-BY-NC-ND 4.0 International license .

Compared to controls (Figure 2, Supplementary Table 2), FLE exhibited lower inferior frontal activation and reduced right angular deactivation $\left(p_{\mathrm{FWE}}<0.05\right)$. Compared to TLE, FLE had higher left posterior temporo-parietal and bilateral occipital activation, and reduced deactivation of the right angular gyrus and bilateral precuneus (all $p_{\mathrm{FWE}}<0.05$ ). Analysis of systems showed no corrected differences between FLE and controls, and between FLE and TLE; at uncorrected thresholds, there was lower left-hemispheric cognitive control activity in FLE than controls ( $p_{\text {unc }}=0.011 ; d=-0.35$ ), and better recruitment of the dorsal attention system in FLE than TLE ( $\left.p_{\text {unc }}=0.031, d=0.40\right)$. In FLE, comparison of gradient curves showed one uncorrected positive deviation from controls at the transmodal apex ( $\left.p_{\text {unc }}=0.017, d=0.32\right)$. There was one uncorrected difference between FLE and TLE at an intermediate gradient bin, with higher task activity in FLE ( $p_{\text {unc }}=0.048, d=0.39$ ).

\section{Verbal working memory fMRI}

In controls, the verbal working memory task elicited bilateral frontoparietal activation, mapping to dorsal attention and control systems $(\beta=0.20 / 0.26, p$ FDR $<0.0001$; Figure 3, Supplementary Fig. 4). Deactivation involved posterior cingulate cortex/precuneus, medial prefrontal cortex, and sensorimotor cortices $(\beta=-0.08, p \mathrm{FDR}=0.002$, somatomotor effects). Gradient profiling showed positive shifts along the intermediate-to-transmodal segments, implicating attentional and executive processing, and decreases at the DMN apex (all $p$ FDR $<0.05)$.

Compared to controls, FLE patients had less frontoparietal activation and reduced deactivation of DMN areas ( $p_{\mathrm{FWE}}<0.05$, Figure 4; Supplementary Table 3). Compared to patients with TLE, those with FLE showed reduced deactivation of posterior DMN areas ( $\left.p_{\mathrm{FWE}}<0.05\right)$. Analysis of systems showed reductions of dorsal attention and cognitive control system activity in FLE than controls $\left(p_{\mathrm{FDR}}<0.001 / 0.019, d=-0.62 /-0.40\right)$. Gradient-stratified task profiles showed localized differences between FLE and controls along intermediate gradient segments $\left(p_{\text {FDR }}<0.05 ; d\right.$ range $=-0.52$ to -0.33$)$. There were no differences between FLE and TLE for analysis of systems and gradients.

\section{Visual working memory fMRI}

In controls, the 1-0Back contrast elicited bilateral frontoparietal activation and deactivation of midline DMN areas. Contrasting high versus low working memory demand (2-1Back) showed increasing recruitment of frontoparietal regions (Figure 3). Analysis of systems identified 
medRxiv preprint doi: https://doi.org/10.1101/2021.02.19.21251501; this version posted February 23,2021 . The copyright holder for this preprint (which was not certified by peer review) is the author/funder, who has granted medRxiv a license to display the preprint in It is made available under a CC-BY-NC-ND 4.0 International license .

dorsal attention and cognitive control system activation $(\beta=0.11 / 0.09, p$ FDR $<0.0001 / 0.0002,1-$ 0Back; $\left.\beta=0.08 / 0.11, p_{\mathrm{FDR}}=0.005 /<0.0001,2-1 \mathrm{Back}\right)$, DMN deactivation for the $1-0 \mathrm{Back}$ contrast $\left(\beta=-0.05, \quad p_{\mathrm{FDR}}=0.023\right)$, and somatomotor deactivation for both contrasts ( $\beta=-0.08$ and $-0.06, p_{\text {FDR }}<0.0001$ and $0.005,1-0$ Back and 2-1Back). Gradient analyses indicated positive activity shifts along its intermediate to transmodal segments, and a significant decrease in correspondence of the default-mode apex (all $p_{\text {FDR }}<0.05$ for both conditions).

For the 1-0Back contrast, the FLE group had increased parietal and dorsolateral frontal activation, and reduced deactivation of anterior DMN areas compared to controls ( $p_{\mathrm{FWE}}<0.05$; Figure 4, Supplementary Table 4). Analysis of systems showed higher cognitive control and DMN activity in FLE than controls ( $\left.p_{\mathrm{FDR}}=0.015 / 0.026, d=0.47 / 0.41\right)$, and increased dorsal attention activity at uncorrected thresholds $\left(p_{\text {unc }}=0.027, d=0.34\right)$. Gradient profiles globally differed in FLE compared to controls (FDA, $p=0.022$ ), with bin-wise analyses showing stronger activation in FLE across most gradient sections $\left(p_{\mathrm{FDR}}<0.05, d\right.$ range $=0.31$ to 0.51$)$. There were no significant differences between FLE and TLE for voxel-based, system or gradient analyses.

For the 2-1Back contrast, FLE showed less frontoparietal activation than controls ( $p_{\mathrm{FWE}}<0.05$; Figure 4; Supplementary Table 5). Across most systems, FLE had pronounced negative deviations from healthy controls, particularly for dorsal attention and cognitive control systems ( $\left.p_{\text {FDR }}<0.0001 / 0.007, d=-0.68 /-0.56\right)$. Gradient-based profiles showed global disorganization of task-related recruitment in FLE compared to controls (FDA, $p=0.034$ ), with widespread involvement of intermediate and transmodal gradient segments (all $p$ FDR $<0.05 ; d$ range $=-0.60$ to -0.32). There were no significant differences between FLE and TLE for voxel-based, system or gradient analyses.

\section{Correlation of fMRI measures with cognitive performance}

Across all domains, we identified significant correlations between cognitive scores and functional imaging metrics. All correlation analyses are detailed in the Supplementary Results. For language fMRI, stronger frontal activation was associated with both higher verbal fluency and naming scores; naming also positively correlated with lateral temporal activation, particularly for verb generation fMRI. Conversely, less deactivation of bilateral precuneus during verbal fluency and right posterior temporal areas during verb generation related to worse fluency and naming performance, respectively (Figure 5; $p_{\mathrm{FWE}}<0.05$ ). Effect across systems 
medRxiv preprint doi: https://doi.org/10.1101/2021.02.19.21251501; this version posted February 23,2021 . The copyright holder for this preprint (which was not certified by peer review) is the author/funder, who has granted medRxiv a license to display the preprint in It is made available under a CC-BY-NC-ND 4.0 International license .

were limited $\left(r_{\text {perm }}=-0.16, p_{\text {unc }}=0.046\right.$, verb generation/naming correlation for the limbic system). For verbal fluency fMRI, gradient-based effects at the transmodal apex were negatively correlated with letter fluency ( $r_{\text {perm }}=-0.17 /-0.19, p=0.036 / 0.026$ for significant bins). For working memory fMRI, digit span/visual 2Back performance scores strongly correlated with: (i) bilateral frontoparietal activation during verbal/2-1Back visual working memory at the voxel level (Figure 5; $p_{\mathrm{FWE}}<0.05$ ); (ii) activity of dorsal attention and cognitive control systems $\left(r_{p e r m}=0.31 / 0.33, p_{\mathrm{FDR}}=0.0007\right.$, for verbal working memory fMRI and digit span; $\rho_{\text {perm }}=0.37 / 0.39, p_{\mathrm{FDR}}=<0.0001 / 0.0001$, for 2-1Back fMRI and visual 2Back performance); (iii) task signal across intermediate and transmodal gradient sections $\left(\mathrm{p}_{F D R}<0.05\right.$, permuted correlation ranges: 0.20 to 0.36 ). Similar patterns were evidenced for correlations between verbal 2Back task performance and verbal working memory fMRI (Supplementary Results).

\section{Correlation of fMRI measures with clinical variables}

For language tasks in FLE, longer epilepsy duration related to: (i) stronger verbal fluency fMRI activity in a rostral left middle frontal area bordering the classical activation map ( $\left.p_{\mathrm{FWE}}<0.05\right)$, possibly reflecting compensatory recruitment; (ii) lesser deactivation of the DMN as a whole $\left(r_{\text {perm }}=0.28, p_{\text {unc }}=0.048\right)$, and (iii) lesser deactivation at the gradient apex (bins 18-20, $r_{\text {perm }}$ range $=0.31$ to $0.37, p_{\text {unc }}=0.010$ to 0.029 ); longer duration was also associated with lesser posterior-temporal and angular deactivation during verb generation $\left(p_{\mathrm{FWE}}<0.05\right)$. For working memory in FLE, we found a significant association between lower bilateral parietal activation during the verbal task and longer disease duration $\left(p_{\mathrm{FWE}}<0.05\right)$. This was paralleled by positive correlations between age at onset and (i) cognitive control activity $\left(r_{\text {perm }}=0.33, p_{\text {unc }}=0.025\right)$, as well as (ii) gradient-based profiles (bins $12-18, r_{\text {perm }}$ range $=0.30$ to $0.35, p_{\text {unc }}=0.026$ to 0.048 ) during verbal working memory. In TLE, earlier age at onset was associated with lower inferior frontal activation during verbal fluency, and longer duration related to lesser deactivation of posterior DMN areas during working memory at the voxel level $\left(p_{\mathrm{FWE}}<0.05\right)$.

Further statistical details are available in the Supplementary Results.

\section{Sensitivity analyses}

a) Subgroup analysis in FLE with FCD: We separately investigated an FLE subgroup with suspected focal cortical dysplasia (FLE-FCD; $n=13$, pathologically confirmed in 8). Across domains and analysis scales, comparisons of the FLE-FCD subgroup to controls produced 
medRxiv preprint doi: https://doi.org/10.1101/2021.02.19.21251501; this version posted February 23, 2021. The copyright holder for this preprint (which was not certified by peer review) is the author/funder, who has granted medRxiv a license to display the preprint in It is made available under a CC-BY-NC-ND 4.0 International license.

results similar to those in the main group comparisons (Supplementary Results, Supplementary Fig. 5).

b) Mitigation of the effects of frontal language laterality: Analysis of language laterality indices (LIs) showed weaker left lateralization of frontal hemispheric dominance for language in FLE compared controls (Table 1). Repeat voxel-based analyses covarying for language LI in frontal regions of interest, however, still yielded significant left frontal activation differences between FLE and controls for both verbal fluency and verb generation tasks $\left(p_{\mathrm{FWE}}<0.05\right.$; Supplementary Table 6).

c) Separate analysis of left and right FLE: Lateralization of the seizure focus may differentially affect cognitive system activity, particularly for verbal tasks. We thus conducted repeat voxellevel analyses separately comparing left and right FLE subgroups to controls. For language tasks, left and right FLE had similar differences compared to controls (Supplementary Fig. 6). Patterns in left and right FLE were also similar for the verbal working memory task. For visual working memory, there were more marked frontoparietal activation and impaired frontal DMN deactivation in left FLE, for the 1-0 Back contrast, and more marked activation decreases in right FLE for the 2-1Back contrast (Supplementary Fig. 6). 
medRxiv preprint doi: https://doi.org/10.1101/2021.02.19.21251501; this version posted February 23,2021 . The copyright holder for this preprint (which was not certified by peer review) is the author/funder, who has granted medRxiv a license to display the preprint in

It is made available under a CC-BY-NC-ND 4.0 International license .

\section{DISCUSSION}

Knowledge of the neurobiological substrates of cognitive impairment in FLE is scarce. Here, we profiled the neural correlates of language and working memory dysfunction in a large FLE sample. Concomitant analysis of a TLE group allowed us to decode shared and syndromespecific effects. Our findings indicate impaired fronto-temporo-parietal activation and impaired DMN deactivation in FLE, and implicate areas across a broad spectrum of functional specialization. Global disorganization of task-related recruitment, as elucidated by system and gradient analyses, was evident for working memory. While patterns of dysfunction largely overlapped across syndromes, we found more prominent alterations of DMN deactivation in FLE, and more marked temporal abnormalities in TLE during verb generation, which entails semantic processing. Task profiles in FLE were detrimentally modulated by clinical characteristics. This study conveys a comprehensive characterization of the neural correlates of cognitive impairment in FLE, paving the way for future analyses of disease subgroups. We provide neural targets that may aid future investigations into cognitive prognostics, and inform the development of novel rehabilitation and therapeutic approaches.

Neuropsychological profiles indicated generalized cognitive impairment in FLE, with poorer performance for functions typically ascribed to the frontal lobes, including working memory, verbal fluency and mental flexibility, and weaker verbal memory and naming, that rely more markedly on temporal lobe processing. Comparison of FLE and TLE showed more prominent executive dysfunction in the former, and more marked impairment of verbal learning and semantic knowledge in the latter. Our findings corroborate evidence of dysexecutive traits and memory difficulties in FLE, $, 10,12$ and indicate that cognitive profiles in FLE and TLE differ. Echoing prior work, ${ }^{4,8,15}$ we suggest that functions that more strongly recruit areas overlapping with the epileptic network are affected more pervasively.

Traditional fMRI activation maps provide a fine-grained account of regional group differences, but do not capture large-scale effects. With our multiscale approach, we also attained systemslevel inference ${ }^{36,62,65}$ and profiled cognition on the backbone of an organizational principle of intrinsic connectivity, the principal gradient. ${ }^{37,66}$ The gradient describes a continuous transition from unimodal sensory to transmodal areas, and offers a compact framework to conceptualize task-related effects in the context of cognitive system hierarchies. ${ }^{40,41,57}$ Our analyses enabled decoding of the neural signatures of cognition from a "local-to-global" perspective, captured the landscape of competing activation and deactivation during cognition, and provide a novel framework to investigate cognitive impairment in epilepsy. 
medRxiv preprint doi: https://doi.org/10.1101/2021.02.19.21251501; this version posted February 23,2021 . The copyright holder for this preprint (which was not certified by peer review) is the author/funder, who has granted medRxiv a license to display the preprint in It is made available under a CC-BY-NC-ND 4.0 International license .

In controls, language tasks elicited left-lateralized activation of middle and inferior frontal gyrus and temporo-parietal cortices, which positively correlated with fluency and naming performance. Systems-level effects captured cognitive control and opercular involvement, and activity shifts along the intermediate to transmodal gradient segments implicated a combination of attentional and high-level executive processing. Suppression of DMN activity was extensive for verbal fluency, which requires executive control, ${ }^{16,67}$ was tracked by negative effects at the transmodal gradient apex, and was neurobehaviorally relevant, as demonstrated by correlations analyses with out-of-scanner performance. Temporo-parietal activation was more marked during verb generation, in light of its semantic demands, ${ }^{68,69}$ and correlated with naming.

Across language tasks, we found reduced activation of the left inferior and middle frontal gyrus in FLE, which represented an isolated abnormality during verb generation, but coexisted with temporal and subcortical differences during verbal fluency. We also observed slightly weaker frontal language lateralization in FLE compared to controls, corroborating findings of prior case series. ${ }^{70,71}$ Repeat group comparisons controlling for frontal language laterality, however, did not change our main results, excluding a substantial influence of interhemispheric frontal language organization on the observed group differences. Thus, dysfunction of the left frontal language core may be a key feature underlying impaired expressive language in FLE. From a neurobiological perspective, such dysfunction may be a result of epileptic activity of frontal origin, with adverse effects on synaptic connections and local computation. Exploratory analyses identified similar disruptions of left-hemispheric activation in left and right FLE. Involvement of left-hemispheric language areas and verbal deficits were previously described in people with right TLE, which led to reconsider earlier views on the sparing of verbal functions in right-hemisphere pathology. ${ }^{16,72-74}$ Along the same lines, it is possible that left frontal language alterations in right FLE may be a consequence of transcallosal propagation of epileptic activity, ${ }^{76}$ given the rapid bilateral spread of frontal lobe seizures. ${ }^{1,75}$

FLE and TLE groups had similar frontal abnormalities during verbal fluency. Frontal language dysfunction thus represents a shared trait, possibly as a downstream consequence of both proximal (frontal) and more distal (temporal) pathology. Notably, we and others previously showed abnormal frontal activation and frontotemporal connectivity during expressive language fMRI in TLE. ${ }^{22,23,77,78}$ Alteration of frontal function in TLE may emerge as propagated abnormality, and could be mediated by microstructural alterations in perisylvian white matter tracts. ${ }^{49,73,74}$ During verb generation, there were differences between FLE and TLE in the semantic processing stream, involving posterior temporo-parietal and occipital 
medRxiv preprint doi: https://doi.org/10.1101/2021.02.19.21251501; this version posted February 23,2021 . The copyright holder for this preprint (which was not certified by peer review) is the author/funder, who has granted medRxiv a license to display the preprint in It is made available under a CC-BY-NC-ND 4.0 International license .

areas. ${ }^{69,79,80}$ More marked impairment during tasks with semantic demands thus appears TLEspecific, and correlates with neuropsychological findings. While frontal language areas represent a common substrate of expressive language dysfunction across TLE and FLE, temporal pathology may thus primarily affect areas in its vicinity, such as posterior language centers, leading to more pervasive dysfunction during tasks that specifically rely on these.

In both working memory tasks, we detected bilateral frontoparietal activation, ${ }^{31,81}$ that mapped on dorsal attention and cognitive control systems, resulted in activity shifts in the intermediate to transmodal gradient sections, and strongly correlated with in-scanner task performance and digit span scores. For both verbal and visual conditions entailing a 2-Back working memory span, FLE exhibited bilateral attenuation of frontoparietal activation and globally altered gradient profiles, which occurred in both left and right FLE. Activation reductions were particularly marked for the $2-1$ Back contrast, and comprised cognitive systems beyond those directly implicated in working memory. While indicating global dysfunction, such widespread effects may also reflect loss of motivation and participant disengagement. The verbal working memory task, however, was less challenging and, though performed slightly less accurately by people with FLE than controls, resulted in satisfactory performance (>80\%) in all groups. Patients with FLE still presented with frontoparietal hypoactivation, more selective for dorsal attention and cognitive control systems. Thus, we suggest that attenuated frontoparietal activation may more parsimoniously reflect inefficient recruitment of areas required for successful task performance. The low-demand visual working memory contrast, on the other hand, was associated with enhanced frontoparietal activation and reduced DMN deactivation in FLE. This sequence of higher and lower activation for easy and difficult task conditions points to cognitive system saturation that already occurs for low-level task demands, and is followed by defective additional recruitment for higher task difficulty levels. Notably, by encompassing altered deactivation of DMN regions, neural processes underlying working memory in FLE already proved inefficient for easier task conditions.

Comparison of FLE and TLE for working memory did not indicate marked group differences. Working memory relies on the activity of distributed, bilateral fronto-temporo-parietal networks. ${ }^{35,82,83}$ It is possible that propagation of ictal and interictal epileptic activity, and consequent long-lasting neural derangements within multiple sites relevant for performance, all result in globally less efficient working memory networks, independent of the location of the area of seizure onset. Future investigation of recent-onset focal epilepsy may clarify 
medRxiv preprint doi: https://doi.org/10.1101/2021.02.19.21251501; this version posted February 23,2021 . The copyright holder for this preprint (which was not certified by peer review) is the author/funder, who has granted medRxiv a license to display the preprint in It is made available under a CC-BY-NC-ND 4.0 International license .

whether the involvement of working memory hubs may be sequential, with earlier effects close to the seizure focus.

Across tasks, we showed impaired deactivation of DMN areas in FLE, and to a lesser extent in TLE. The DMN subserves processes including self-awareness, mind-wandering, and cognition supported by internal representations. ${ }^{84-86} \mathrm{DMN}$ deactivation and anti-correlation between activity patterns in DMN regions and frontoparietal areas were described for tasks with executive demands. ${ }^{33,87,88}$ Alterations in such processes were previously identified in a spectrum of psychiatric disorders, including autism ${ }^{89,90}$ and schizophrenia, ${ }^{91,92}$ and may reflect suboptimal distribution of neural resources during goal-directed cognition. ${ }^{93} \mathrm{We}$ and others previously showed altered DMN deactivation during working memory in JME and pediatric TLE. ${ }^{47,94}$ Our current findings in FLE underscore the vulnerability of the DMN across the epilepsy spectrum, and indicate altered DMN deactivation profiles as a possible transsyndromic marker. We previously documented an influence of ASMs on task-related deactivation during language and working memory. ${ }^{44,45,95}$ Such effects, however, largely spared midline anterior and posterior DMN areas, which, in this study, were associated with prominent differences between FLE and controls, and between FLE and TLE. Interestingly, alterations of task-related deactivation, mostly encompassing DMN nodes, were more marked in FLE than TLE. Future connectivity-based analyses may better characterize the underlying sources of such phenomenon; a potential explanation may lie in the differential connectivity profiles of specific DMN hubs, such as the medial prefrontal cortex, that is strongly embedded within midline DMN, and likely to be involved in the propagation network of frontal seizures. ${ }^{75}$ Correlation analyses showed that disease load, as tracked by age at onset and epilepsy duration, may modulate severity of both activation and deactivation profiles in FLE. Such effects were particularly evident for verbal working memory. Prior work has identified detrimental associations between cognitive function and early age at epilepsy onset, ${ }^{96-99}$ that are possibly linked to disrupted white matter maturation. ${ }^{100,101}$ In our study, associations were more evident for functions that have a prolonged maturational trajectory, such as working memory, which depends on the myelination of long-range fiber tracts. ${ }^{102,103}$

The co-occurrence of impaired frontoparietal activation and DMN deactivation in FLE mirrors findings of studies comparing healthy older adults ( 70 years) to younger individuals. ${ }^{104,105} \mathrm{As}$ the mean age in our FLE sample was $\sim 30$ years, this raises the question of whether the identified traits may reflect a functional marker of accelerated brain aging. If proven by future work, such 
medRxiv preprint doi: https://doi.org/10.1101/2021.02.19.21251501; this version posted February 23,2021 . The copyright holder for this preprint (which was not certified by peer review) is the author/funder, who has granted medRxiv a license to display the preprint in

It is made available under a CC-BY-NC-ND 4.0 International license .

phenomenon would dovetail with recent evidence of accelerated grey matter loss in people with focal epilepsy, which revived the "disease progression" hypothesis. ${ }^{106-109}$

Our study has several strengths, including the use of large samples, robust methodology, comprehensive mapping of function from local to global perspectives, direct comparison of patient groups, and several sensitivity analyses. Our study also has limitations. The FLE group was heterogeneous in terms of etiology and MRI findings, but is representative of the spectrum of FLE patients assessed in tertiary centers..$^{3,9,110}$ In addition, sensitivity analyses in the FLEFCD patient subgroup largely corroborated our main findings. Future work is encouraged to disentangle cognitive alterations specific to distinct etiologies, and to patient subgroups based on sub-lobar lesion location or patterns of seizure semiology. ${ }^{75}$ The language tasks were covert, which prevented online performance monitoring. However, these tasks were previously validated, ${ }^{49,77}$ are extensively used clinically, ${ }^{111,112}$ and captured interindividual differences in out-of-scanner fluency and naming performance in our study. Patients with FLE and TLE were drug-resistant, taking ASMs in various combinations. We previously described compound- and syndrome-specific effects of ASMs on cognitive networks. ${ }^{95,113}$ FLE and TLE groups were balanced for medications with known detrimental (topiramate/zonisamide) or more favorable (levetiracetam) cognitive network profiles. ${ }^{44,45}$ As for comparisons with controls, it is possible that impaired task-related activation in FLE (and TLE) may be partially influenced by ASMs. As discussed earlier, however, previously described ASM-related effects on task deactivation patterns largely spared areas showing marked intergroup differences in this study. Finally, we provided evidence of associations between age at onset, disease duration and task-related network phenotypes, which suggests disease-related mediating factors other than ASMs. Future longitudinal work, including the assessment of drug-naïve patients, may better characterize the contribution of ASMs to cognitive system dysfunction in epilepsy.

\section{CONCLUSION}

Our study maps language and working memory dysfunction in FLE, showing local, systemslevel, and global abnormalities that indicate an altered interplay between task-related cognitive system activation and deactivation. While patterns of dysfunction in FLE and TLE largely overlap, activity of posterior language centers and profiles of default-mode deactivation are more and less favorably affected in FLE than TLE. This work bridges a substantial knowledge gap in the epilepsy literature, and delivers neural markers that can be validated in the context of cognitive prognostics, and may serve as targets for future development of targeted treatment. 
medRxiv preprint doi: https://doi.org/10.1101/2021.02.19.21251501; this version posted February 23,2021 . The copyright holder for this preprint (which was not certified by peer review) is the author/funder, who has granted medRxiv a license to display the preprint in

It is made available under a CC-BY-NC-ND 4.0 International license .

\section{CITATION DIVERSITY STATEMENT}

Recent work in several fields of science has identified a bias in citation practices such that papers from women and other minority scholars are under-cited relative to the number of such papers in the field. ${ }^{114-118}$ Here we sought to proactively consider choosing references that reflect the diversity of the field in thought, form of contribution, gender, race, ethnicity and other factors. First, we obtained the predicted gender of the first and last author of each reference by using databases that store the probability of a first name being carried by a woman ${ }^{118,119}$. By this measure (and excluding self-citations to the first and last authors of our current paper), our references contain $10.71 \%$ woman(first)/woman(last), $10.71 \%$ man/woman, $27.38 \%$ woman/man, and $51.19 \%$ man/man. This method is limited in that a) names, pronouns and social media profiles used to construct the databases may not, in every case, be indicative of gender identity, and b) it cannot account for intersex, non-binary, or transgender people. Second, we obtained predicted racial/ethnic category of the first and last author of each reference by databases that store the probability of a first and last name being carried by an author of color. ${ }^{120,121}$ By this measure (and excluding self-citations), our references contain $8.05 \%$ author of color (first)/author of color(last), $13.50 \%$ white author/author of color, $18.88 \%$ author of color/white author, and 59.57\% white author/white author. This method is limited in that a) names, Census entries, and Wikipedia profiles used to make the predictions may not be indicative of racial/ethnic identity, and b) it cannot account for Indigenous and mixed-race authors, or those who may face differential biases due to the ambiguous racialization or ethnicization of their names. We look forward to future work that could help us to better understand how to support equitable practices in science.

\section{ACKNOWLEDGEMENTS}

We thank our patients and controls for their participation in this study, and the radiographers at the Epilepsy Society MRI Unit, Philippa Bartlett, Jane Burdett, and Elaine Williams for their help during data acquisition. We also thank Jason Stretton for data acquisition. Dr. Jonathan O'Muircheartaigh and Professor Mark P. Richardson are acknowledged for previous collaborative research initiatives. Alexander Lowe is acknowledged for insightful discussions during prior work. Sara Larivière and Reinder Vos De Wael are acknowledged for helpful conversations on functional gradient analyses. 
medRxiv preprint doi: https://doi.org/10.1101/2021.02.19.21251501; this version posted February 23, 2021. The copyright holder for this preprint (which was not certified by peer review) is the author/funder, who has granted medRxiv a license to display the preprint in It is made available under a CC-BY-NC-ND 4.0 International license .

\section{FUNDING}

Participant recruitment was funded through the Wellcome Trust (Project Grants No 079474 and 083148 to MJK and JSD). We are grateful to the Epilepsy Society for supporting the Epilepsy Society MRI scanner. This research was also supported by the National Institute for Health Research University College London Hospitals Biomedical Research Centre. LC acknowledges support from a Brain Research UK PhD scholarship (Award 14181), and from a Berkeley Fellowship jointly awarded by University College London and Gonville and Caius College, Cambridge. XH acknowledges grant support from the American Epilepsy Society. KT was supported by fellowships of the European Academy of Neurology and the Austrian Society of Neurology (OEGN). GPW was supported by the MRC (G0802012, MR/M00841X/1). LC, XH and DSB acknowledge support from the NINDS (R01-NS099348); DSB acknowledges support from the John D. and Catherine T. MacArthur Foundation, the Alfred P. Sloan Foundation, the Paul Allen Family Foundation, and the ISI Foundation. BCB acknowledges research funding from the SickKids Foundation (NI17-039), the National Sciences and Engineering Research Council of Canada (NSERC; Discovery-1304413), CIHR (FDN-154298), Azrieli Center for Autism Research (ACAR), BrainCanada, the Montreal Neurological Institute, as well as Fonds de la recherche du Quebec-Santé (FRQ-S) and the Canada Research Chairs program. The funders had no role in study design, data collection and analysis, decision to publish, or preparation of the manuscript.

\section{COMPETING INTERESTS}

The authors report no competing interests in relation to this submission.

\section{SUPPLEMENTARY MATERIAL}

Supplementary material is available for this manuscript. 
medRxiv preprint doi: https://doi.org/10.1101/2021.02.19.21251501; this version posted February 23, 2021. The copyright holder for this preprint (which was not certified by peer review) is the author/funder, who has granted medRxiv a license to display the preprint in It is made available under a CC-BY-NC-ND 4.0 International license.

Table 1. Demographic, clinical and neuropsychological data

\begin{tabular}{|c|c|c|c|c|c|c|}
\hline & $\begin{array}{c}\text { CTR } \\
(\mathbf{n}=52)\end{array}$ & $\underset{(\mathrm{n}=56)}{\mathbf{F L E}}$ & $\underset{(n=64)}{\text { TLE }}$ & $\begin{array}{c}\text { Test } \\
\text { statistic } \\
\left(F, H \text { or } \chi^{2}\right)\end{array}$ & $P$ value & $\begin{array}{l}\text { Post-hoc tests } \\
\text { (Bonferroni } \\
\text { corrected) }\end{array}$ \\
\hline $\begin{array}{c}\text { Age at scan } \\
{[\text { years, mean }(\mathrm{SD})]}\end{array}$ & $\begin{array}{c}34.1 \\
(10.4)\end{array}$ & $\begin{array}{c}33.4 \\
(10.2)\end{array}$ & $\begin{array}{c}39.2 \\
(10.7)\end{array}$ & 5.6 & 0.005 & $\begin{array}{l}\text { FLE/CTR: } 1.00 \\
\text { FLE/TLE: } \mathbf{0 . 0 0 8} \\
\text { TLE/CTR: } 0.029\end{array}$ \\
\hline $\operatorname{Sex}(F / M)$ & $30 / 22$ & $29 / 27$ & $44 / 20$ & 3.7 & 0.15 & \\
\hline Handedness (L/R/A) & $6 / 46 / 0$ & $5 / 49 / 2$ & $10 / 52 / 2$ & 3.0 & 0.59 & \\
\hline Side of seizure focus (L/R) & - & $30 / 26$ & $34 / 30$ & 0.0 & 1.00 & \\
\hline $\begin{array}{c}\text { Etiological categories } \\
\text { (non-lesional/FCD/DNET/ } \\
\text { glial tumor/other } † / H S \text { ) }\end{array}$ & - & $\begin{array}{c}29 / 13 / 6 / \\
3 / 5 / 0\end{array}$ & $\begin{array}{l}0 / 0^{\circ} / 0^{\circ} / \\
0 / 0 / 64\end{array}$ & - & - & \\
\hline $\begin{array}{l}\text { Age of epilepsy onset } \\
\text { [median (IQR)] }\end{array}$ & - & $\begin{array}{l}10.0 \\
(6.0)\end{array}$ & $\begin{array}{c}13.0 \\
(11.8)\end{array}$ & 2.3 & 0.13 & \\
\hline $\begin{array}{l}\text { Duration of epilepsy } \\
\text { [median (IQR)] }\end{array}$ & - & $\begin{array}{c}21.0 \\
(15.0)\end{array}$ & $\begin{array}{l}22.5 \\
(24.3)\end{array}$ & 0.6 & 0.44 & \\
\hline $\begin{array}{c}\text { AEDs } \\
{[\text { median }(\mathrm{IQR})]}\end{array}$ & - & $\begin{array}{l}3.0 \\
(1.0)\end{array}$ & $\begin{array}{l}2.5 \\
(1.0)\end{array}$ & 1.3 & 0.25 & \\
\hline $\begin{array}{c}\text { Topiramate/Zonisamide } \\
\text { [yes/no] }\end{array}$ & - & $15 / 41$ & $12 / 52$ & 1.1 & 0.38 & \\
\hline $\begin{array}{l}\text { Levetiracetam } \\
\text { [yes/no] }\end{array}$ & - & $29 / 27$ & $41 / 23$ & 1.9 & 0.20 & \\
\hline $\begin{array}{c}\text { Frontal language LI } \\
\text { [Verbal fluency fMRI, } \\
\text { median (IQR)] }\end{array}$ & $\begin{array}{c}0.79 \\
(0.32)\end{array}$ & $\begin{array}{c}0.67 \\
(0.56)\end{array}$ & $\begin{array}{c}0.76 \\
(0.29)\end{array}$ & 10.5 & 0.005 & $\begin{array}{l}\text { FLE/CTR: } \mathbf{0 . 0 0 4} \\
\text { FLE/TLE: } 0.094 \\
\text { TLE/CTR: } 0.744\end{array}$ \\
\hline $\begin{array}{c}\text { Frontal language LI } \\
\text { [Verb generation fMRI, } \\
\text { median (IQR)] }\end{array}$ & $\begin{array}{c}0.81 \\
(0.23)\end{array}$ & $\begin{array}{c}0.65 \\
(1.15)\end{array}$ & $\begin{array}{c}0.70 \\
(0.41)\end{array}$ & 9.1 & 0.01 & $\begin{array}{c}\text { FLE/CTR: } \mathbf{0 . 0 1 9} \\
\text { FLE/TLE: } 1.00 \\
\text { TLE/CTR: } \mathbf{0 . 0 3 0}\end{array}$ \\
\hline $\begin{array}{l}\text { IQ (NART) } \\
{[\text { mean (SD)] }}\end{array}$ & $\begin{array}{c}112.1 \\
(8.8)\end{array}$ & $\begin{array}{c}99.7 \\
(11.0)\end{array}$ & $\begin{array}{c}97.3 \\
(12.3)\end{array}$ & 24.2 & $\begin{array}{c}3.3 \mathrm{e}- \\
09^{*}\end{array}$ & $\begin{array}{c}\text { FLE/CTR: 1.0e-06 } \\
\text { FLE/TLE: } 0.58 \\
\text { TLE/CTR: } \mathbf{1 . 5 e - 0 9}\end{array}$ \\
\hline $\begin{array}{l}\text { Letter Fluency } \\
{[\text { mean (SD)] }}\end{array}$ & $\begin{array}{l}18.8 \\
(6.1)\end{array}$ & $\begin{array}{l}10.9 \\
(4.9)\end{array}$ & $\begin{array}{l}13.2 \\
(6.0)\end{array}$ & 23.8 & $\begin{array}{l}3.5 \mathrm{e}- \\
09^{*}\end{array}$ & $\begin{array}{l}\text { FLE/CTR: 1.3e-9 } \\
\text { FLE/TLE: } 0.25 \\
\text { TLE/CTR: } \mathbf{3 . 0 e - 0 6}\end{array}$ \\
\hline $\begin{array}{l}\text { Category Fluency } \\
\text { [mean (SD)] }\end{array}$ & $\begin{array}{l}24.0 \\
(4.9)\end{array}$ & $\begin{array}{l}18.2 \\
(5.9)\end{array}$ & $\begin{array}{l}17.9 \\
(5.1)\end{array}$ & 19.4 & $\begin{array}{l}8.8 \mathrm{e}- \\
08^{*}\end{array}$ & $\begin{array}{c}\text { FLE/CTR: 1.0e-06 } \\
\text { FLE/TLE: } 1.00 \\
\text { TLE/CTR: } \mathbf{2 . 3 e - 0 7}\end{array}$ \\
\hline $\begin{array}{l}\text { Graded Naming Test } \\
{[\text { mean }(\mathrm{SD})]}\end{array}$ & $\begin{array}{l}22.0 \\
(3.6)\end{array}$ & $\begin{array}{l}16.7 \\
(4.3)\end{array}$ & $\begin{array}{l}14.3 \\
(5.7)\end{array}$ & 42.7 & $\begin{array}{l}3.8 \mathrm{e}- \\
14^{*}\end{array}$ & $\begin{array}{l}\text { FLE/CTR: 2.0e-06 } \\
\text { FLE/TLE: 4.4e-04 } \\
\text { TLE/CTR: 7.8e-16 }\end{array}$ \\
\hline $\begin{array}{l}\text { Vocabulary } \\
{[\text { mean }(\mathrm{SD})]}\end{array}$ & - & $\begin{array}{c}9.1 \\
(3.7)\end{array}$ & $\begin{array}{c}8.0 \\
(2.8)\end{array}$ & $\begin{array}{l}-1.8^{\S /-} \\
5.7 \S / 3.0\end{array}$ & - & $\begin{array}{c}\text { FLE/norm: } 0.23 \\
\text { FLE/TLE: } 0.26 \\
\text { TLE/norm: } 1.2 \mathrm{e}-06\end{array}$ \\
\hline $\begin{array}{l}\text { Similarities } \\
{[\text { mean }(\mathrm{SD})]}\end{array}$ & - & $\begin{array}{c}8.3 \\
(3.2)\end{array}$ & $\begin{array}{c}8.5 \\
(2.8)\end{array}$ & $\begin{array}{l}-3.99^{\S} /- \\
4.3^{8} / 0.3\end{array}$ & - & $\begin{array}{l}\text { FLE/norm: } 9.5 \mathrm{e}-04 \\
\text { FLE/TLE: } 1.00 \\
\text { TLE/norm: } 1.7 \mathrm{e}-04\end{array}$ \\
\hline $\begin{array}{l}\text { Digit Span } \\
{[\text { mean }(\mathrm{SD})]}\end{array}$ & $\begin{array}{l}11.4 \\
(2.6)\end{array}$ & $\begin{array}{l}8.0 \\
(2.9)\end{array}$ & $\begin{array}{l}8.0 \\
(2.2)\end{array}$ & 25.1 & $\begin{array}{l}2.0 \mathrm{e}- \\
09^{*}\end{array}$ & $\begin{array}{c}\text { FLE/CTR: 8.2e-09 } \\
\text { FLE/TLE: } 1.00 \\
\text { TLE/CTR: } 8.2 \mathrm{e}-\mathbf{0 9}\end{array}$ \\
\hline $\begin{array}{l}\text { Trail Making A^^} \\
\quad[\text { mean }(\mathrm{SD})]\end{array}$ & $\begin{array}{l}28.1 \\
(8.8)\end{array}$ & $\begin{array}{l}41.4 \\
(17.8)\end{array}$ & $\begin{array}{c}35.9 \\
(14.7)\end{array}$ & 10.7 & $\begin{array}{l}7.3 e- \\
05^{*}\end{array}$ & $\begin{array}{c}\text { FLE/CTR: 2.7e-05 } \\
\text { FLE/TLE: } 0.13 \\
\text { TLE/CTR: } \mathbf{0 . 0 2 2}\end{array}$ \\
\hline $\begin{array}{l}\text { Trail Making B-A^^} \\
{[\text { mean }(\mathrm{SD})]}\end{array}$ & $\begin{array}{l}25.8 \\
(11.2)\end{array}$ & $\begin{array}{l}69.0 \\
(55.5)\end{array}$ & $\begin{array}{l}47.4 \\
(36.5)\end{array}$ & 18.6 & $\begin{array}{l}1.7 \mathrm{e}- \\
07^{*}\end{array}$ & $\begin{array}{c}\text { FLE/CTR: } \mathbf{3 . 2 e - 0 8} \\
\text { FLE/TLE: } \mathbf{0 . 0 1 5} \\
\text { TLE/CTR: } \mathbf{0 . 0 0 2}\end{array}$ \\
\hline $\begin{array}{l}\text { List Learning (A1-5) } \\
\quad[\text { mean }(\mathrm{SD})]\end{array}$ & $\begin{array}{l}58.1 \\
(8.2)\end{array}$ & $\begin{array}{l}49.9 \\
(9.6)\end{array}$ & $\begin{array}{c}43.9 \\
(10.8)\end{array}$ & 26.0 & $\begin{array}{l}1.7 \mathrm{e}- \\
09^{*}\end{array}$ & $\begin{array}{c}\text { FLE/CTR: 1.0e-04 } \\
\text { FLE/TLE: } \mathbf{0 . 0 1 0} \\
\text { TLE/CTR: 8.04e-11 }\end{array}$ \\
\hline $\begin{array}{l}\text { List Learning (A6) } \\
\text { [mean (SD)] }\end{array}$ & $12.1(3.0)$ & $\begin{array}{l}10.4 \\
(3.4)\end{array}$ & $\begin{array}{c}8.4 \\
(3.5)\end{array}$ & 15.5 & $\begin{array}{l}1.5 \mathrm{e}- \\
06^{*}\end{array}$ & $\begin{array}{c}\text { FLE/CTR: } 0.10 \\
\text { FLE/TLE: } \mathbf{0 . 0 0 2} \\
\text { TLE/CTR: } \mathbf{6 . 4 e - 0 7}\end{array}$ \\
\hline $\begin{array}{l}\text { Design Learning (A1-5) } \\
\text { [mean (SD)] }\end{array}$ & $\begin{array}{l}38.8 \\
(5.1)\end{array}$ & $\begin{array}{l}32.3 \\
(9.6)\end{array}$ & $\begin{array}{l}31.4 \\
(8.0)\end{array}$ & 11.7 & $\begin{array}{l}\text { 3.0e- } \\
05^{*}\end{array}$ & $\begin{array}{l}\text { FLE/CTR: 1.2e-04 } \\
\text { FLE/TLE: } 1.00 \\
\text { TLE/CTR: } \mathbf{1 . 2 e - 0 4}\end{array}$ \\
\hline $\begin{array}{l}\text { Design Learning (A6) } \\
{[\text { mean }(\mathrm{SD})]}\end{array}$ & $\begin{array}{c}8.2 \\
(1.4)\end{array}$ & $\begin{array}{l}6.8 \\
(2.4)\end{array}$ & $\begin{array}{c}6.4 \\
(2.6)\end{array}$ & 6.8 & $0.002 *$ & $\begin{array}{c}\text { FLE/CTR: } \mathbf{0 . 0 0 5} \\
\text { FLE/TLE: } 1.00 \\
\text { TLE/CTR: } \mathbf{0 . 0 0 4}\end{array}$ \\
\hline $\begin{array}{c}\text { Verbal WM task-Verbal } \\
\text { Monitoring }\end{array}$ & $\begin{array}{c}100.0 \\
(0.0)\end{array}$ & $\begin{array}{l}100.0 \\
(7.1)\end{array}$ & $\begin{array}{l}100.0 \\
(7.1)\end{array}$ & 1.3 & $0.53^{*}$ & \\
\hline
\end{tabular}


medRxiv preprint doi: https://doi.org/10.1101/2021.02.19.21251501; this version posted February 23, 2021. The copyright holder for this preprint (which was not certified by peer review) is the author/funder, who has granted medRxiv a license to display the preprint in It is made available under a CC-BY-NC-ND 4.0 International license

\begin{tabular}{|c|c|c|c|c|c|c|}
\hline [median (IQR)] & & & & & & \\
\hline $\begin{array}{c}\text { Verbal WM task - } 2 \text { Back } \\
{[\text { median (IQR) }]}\end{array}$ & $\begin{array}{c}100.0 \\
(9.6)\end{array}$ & $\begin{array}{c}92.3 \\
(19.2)\end{array}$ & $\begin{array}{c}84.6 \\
(28.9)\end{array}$ & 16.4 & $\begin{array}{c}\text { 3.6e- } \\
04 *\end{array}$ & $\begin{array}{c}\text { FLE/CTR: } \mathbf{0 . 0 1 4} \\
\text { FLE/TLE: } 1.00 \\
\text { TLE/CTR: } \mathbf{2 . 4 e - 0 4}\end{array}$ \\
\hline $\begin{array}{c}\text { Visual WM task - o Back } \\
{[\text { median (IQR)] }}\end{array}$ & $\begin{array}{l}94.7 \\
(7.3)\end{array}$ & $\begin{array}{l}94.7 \\
(8.7)\end{array}$ & $\begin{array}{c}90.7 \\
(15.0)\end{array}$ & 12.1 & $0.002 *$ & $\begin{array}{l}\text { FLE/CTR: } 1.00 \\
\text { FLE/TLE: } \mathbf{0 . 0 2 7} \\
\text { TLE/CTR: } \mathbf{0 . 0 0 4}\end{array}$ \\
\hline $\begin{array}{c}\text { Visual WM task - } 1 \text { Back } \\
{[\text { median (IQR)] }}\end{array}$ & $\begin{array}{l}90.0 \\
(20.0)\end{array}$ & $\begin{array}{c}78.6 \\
(38.6)\end{array}$ & $\begin{array}{c}72.9 \\
(42.1)\end{array}$ & 14.8 & $\begin{array}{c}7.5 \mathrm{e}- \\
04 *\end{array}$ & $\begin{array}{c}\text { FLE/CTR: } \mathbf{0 . 0 1 3} \\
\text { FLE/TLE: } 1.00 \\
\text { TLE/CTR: } \mathbf{0 . 0 0 1}\end{array}$ \\
\hline $\begin{array}{c}\text { Visual WM task - } 2 \text { Back } \\
{[\text { median (IQR)] }}\end{array}$ & $\begin{array}{c}73.8 \\
(37.7)\end{array}$ & $\begin{array}{c}43.1 \\
(28.5)\end{array}$ & $\begin{array}{c}40.0 \\
(44.6)\end{array}$ & 22.7 & $\begin{array}{c}2.1 \mathrm{e}- \\
05^{*}\end{array}$ & $\begin{array}{c}\text { FLE/CTR: 1.8e-04 } \\
\text { FLE/TLE: } 1.00 \\
\text { TLE/CTR: } \mathbf{5 . 7 e - 0 5}\end{array}$ \\
\hline
\end{tabular}

Abbreviations: CTR= healthy controls; DNET= dysembryoplastic neuroepithelial tumor; $\mathrm{FCD}=$ suspected focal cortical dysplasia; FLE= frontal lobe epilepsy; HS= hippocampal sclerosis; $\mathrm{IQ}=$ intelligence quotient; $\mathrm{IQR}=$ interquartile range; $\mathrm{LI}=$ laterality index; NART= National Adult Reading Test; norm= normative ranges (Wechsler scale); SD = standard deviation; $\mathrm{TLE}=$ temporal lobe epilepsy; WM= working memory. Categorical variables were compared with Fisher's exact test $\left(\chi^{2}\right.$ statistic is reported). Continuous normally/non-normally distributed demographic variables are reported as mean $(\mathrm{SD}) /$ median (IQR), and were compared via ANOVA ( $F$ statistic)/Kruskal-Wallis test ( $H$ statistic), respectively. Pairwise deletion was applied in case of missing data. Age at onset (and, consequently, duration) could not be accurately estimated in 5 patients with FLE. For details about computation of language laterality indices, see Supplementary Methods.

Neuropsychological test scores were compared via ANCOVA, using age and sex as covariates, except for: (i) digit span scores, already adjusted for age (as per Wechsler score scales), for which ANCOVA with sex as covariate was used; (ii) Vocabulary and Similarities, for which: one-sample $t$-tests (§) assessed deviation of FLE and TLE data from normative scores as provided by the Wechsler Adult Intelligence Scale (Supplementary Methods), and ANCOVA with sex as covariate was used to compare FLE to TLE.

$\dagger$ One patient with possible periventricular nodular heterotopia, and five with miscellaneous MRI abnormalities (described in detail in the Supplementary Methods); ${ }^{\circ}$ Hippocampal sclerosis coexisted with DNET in three patients (one left/two right), and with a possible FCD in one patient (right). ^ Statistics for Trail Making Test A and B-A were carried out on logtransformed data, but raw data are provided in the table to ensure comparability with published literature. Working memory task performance measures were compared via Kruskal-Wallis tests. * $P$-values for group comparisons across neuropsychological and task performance measures were adjusted for multiple comparisons via the False Discovery Rate (FDR) procedure. Post-hoc tests are all Bonferroni-corrected. 
medRxiv preprint doi: https://doi.org/10.1101/2021.02.19.21251501; this version posted February 23, 2021. The copyright holder for this preprint (which was not certified by peer review) is the author/funder, who has granted medRxiv a license to display the preprint in perpetuity.

It is made available under a CC-BY-NC-ND 4.0 International license .

Table 2. Voxel-based group comparisons and association analyses: further details

\begin{tabular}{|c|c|c|c|}
\hline $\begin{array}{l}\text { Voxel-based } \\
\text { Analysis }\end{array}$ & Statistical test & Regions of interest (ROIs) & Covariates \\
\hline \multicolumn{4}{|l|}{ Group Comparisons } \\
\hline \multicolumn{4}{|l|}{$\begin{array}{c}\text { Language fMRI } \\
\text { (all contrasts) }\end{array}$} \\
\hline FLE vs CTR & $\begin{array}{l}\text { Two-tailed } \\
\text { two sample } \\
\text { permutation t-tests }\end{array}$ & $\begin{array}{l}\text { Frontal Language ROIs: IFG orbitalis; IFG; MFG } \\
\text { Temporo-parietal Language ROIs: anterior temporal; middle- } \\
\text { anterior temporal; middle-posterior temporal; posterior } \\
\text { temporal; angular* } \\
\text { "Task-negative" ROIs: anterior (medial prefrontal cortex, } \\
\text { encompassing anterior DMN areas); posterior (posterior } \\
\text { cingulate cortex/precuneus, encompassing posterior DMN } \\
\text { areas) }\end{array}$ & Age, sex \\
\hline FLE $v s$ TLE & $\begin{array}{c}\text { Two-tailed } \\
\text { two sample } \\
\text { permutation t-tests }\end{array}$ & As in the cell above & $\begin{array}{l}\text { Age, sex, side } \\
\text { of epilepsy }\end{array}$ \\
\hline $\begin{array}{l}\text { TLE versus CTR } \\
\text { (Suppl.) }\end{array}$ & $\begin{array}{c}\text { Two-tailed } \\
\text { two sample } \\
\text { permutation t-tests }\end{array}$ & As in the cell above & Age, sex \\
\hline \multicolumn{4}{|l|}{$\begin{array}{c}\text { Working memory fMRI } \\
\text { (all contrasts) }\end{array}$} \\
\hline FLE vs CTR & $\begin{array}{l}\text { Two-tailed } \\
\text { two sample } \\
\text { permutation t-tests }\end{array}$ & $\begin{array}{l}\text { Frontal WM ROIs: dorsolateral prefrontal (BA 9/46, 44); } \\
\text { frontal eye fields (BA 6,8) } \\
\text { Parietal WM ROI: superior/inferior parietal lobule } \\
\text { "Task-negative" ROIs: anterior (medial prefrontal cortex, } \\
\text { encompassing anterior DMN areas); posterior (posterior } \\
\text { cingulate cortex/precuneus, encompassing posterior DMN } \\
\text { areas)^ }\end{array}$ & Age, sex \\
\hline FLE $v s$ TLE & $\begin{array}{c}\text { Two-tailed } \\
\text { two sample } \\
\text { permutation t-tests }\end{array}$ & As in the cell above & $\begin{array}{l}\text { Age, sex, side } \\
\text { of epilepsy }\end{array}$ \\
\hline $\begin{array}{l}\text { TLE vs CTR } \\
\quad \text { (Suppl.) }\end{array}$ & $\begin{array}{c}\text { Two-tailed } \\
\text { two sample } \\
\text { permutation t-tests }\end{array}$ & As in the cell above & Age, sex \\
\hline \multicolumn{4}{|l|}{$\begin{array}{c}\text { Multiple regression } \\
\text { analyses }\end{array}$} \\
\hline $\begin{array}{l}\text { (1) Verbal fluency fMRI } \\
\text { \& letter fluency; } \\
\text { (2) Verbal fluency fMRI } \\
\text { \& naming }\end{array}$ & $\begin{array}{l}\text { Multiple regression, } \\
\text { permutation based }\end{array}$ & $\begin{array}{l}\text { Frontal Language ROIs: IFG orbitalis; IFG; } M F G \\
\text { Temporo-parietal Language ROIs: anterior temporal; middle- } \\
\text { anterior temporal; middle-posterior temporal; posterior } \\
\text { temporal; angular } \\
\text { "Task-negative" ROIs: anterior (medial prefrontal cortex: } \\
\text { anterior DMN); posterior (posterior cingulate cortex/precuneus: } \\
\text { posterior DMN) }\end{array}$ & $\begin{array}{l}\text { Age, sex, } \\
\text { group }\end{array}$ \\
\hline $\begin{array}{l}\text { (1) Verb generation } \\
\text { fMRI \& category } \\
\text { fluency } \\
\text { (2) Verb generation } \\
\text { fMRI \& naming }\end{array}$ & $\begin{array}{l}\text { Multiple regression, } \\
\text { permutation based }\end{array}$ & As in the cell above & $\begin{array}{l}\text { Age, sex, } \\
\text { group }\end{array}$ \\
\hline $\begin{array}{c}\text { (1) Verbal WM fMRI \& } \\
\text { digit span } \\
\text { (2) Verbal WM fMRI \& } \\
\text { verbal 2-Back }\end{array}$ & $\begin{array}{l}\text { Multiple regression, } \\
\text { permutation based }\end{array}$ & $\begin{array}{l}\text { Frontal WM ROIs: dorsolateral prefrontal, frontal eye fields } \\
\text { Parietal WM ROI: superior/inferior parietal lobule } \\
\text { "Task-negative" ROIs: anterior (medial prefrontal cortex: } \\
\text { anterior DMN); posterior (posterior cingulate cortex/precuneus: } \\
\text { posterior DMN) }\end{array}$ & $\begin{array}{l}\text { Age, sex, } \\
\text { group }\end{array}$ \\
\hline $\begin{array}{c}\text { Visual WM fMRI (2- } \\
\text { 1Back) \& visual 2-Back }\end{array}$ & $\begin{array}{l}\text { Multiple regression, } \\
\text { permutation based }\end{array}$ & As in the cell above & $\begin{array}{l}\text { Age, sex, } \\
\text { group }\end{array}$ \\
\hline
\end{tabular}

Abbreviations: $\mathrm{BA}=$ Brodmann Area; $\mathrm{CTR}=$ controls; $\mathrm{DMN}=$ default-mode network; FLE= frontal lobe epilepsy; IFG= inferior frontal gyrus; $\mathrm{MFG}=$ middle frontal gyrus; ROI= region of interest; Suppl.= Supplementary; TLE= temporal lobe epilepsy; WM= working memory. For all multiple regression analyses probing associations between age at onset/disease duration and task fMRI in FLE, we used the same ROIs as in multiple regression analyses with cognitive performance measures, along with sex and side of the epileptic focus as nuisance covariates. For all ROI-based analyses, $p$-values were 
medRxiv preprint doi: https://doi.org/10.1101/2021.02.19.21251501; this version posted February 23,2021 . The copyright holder for this preprint (which was not certified by peer review) is the author/funder, who has granted medRxiv a license to display the preprint in

It is made available under a CC-BY-NC-ND 4.0 International license .

FWE-corrected voxel-wise within ROI; statistical significance was set at two-tailed $p_{\text {FWE }}<0.05$. For further details, see Methods and Supplementary Methods. * left posterior temporal and angular gyrus largely belong to the task deactivation map for verbal fluency, but not for verb generation; ^ a small portion of the dorsal precuneus, which formally belongs to the posterior task-negative ROI, does display task-related activation during WM. Further details are provided in the Supplementary Tables.

\section{FIGURE LEGENDS}

\section{Figure 1. Language fMRI: task effects in controls}

The upper and lower panels show task effects in controls (CTR) for verbal fluency and verb generation fMRI, respectively. Left-sided panels show voxel-based activation (warm colors) and deactivation (cold colors) in controls, as derived from one-sample $t$-tests. Brain renders show maps at $\mathrm{p}<0.001$, with an extent threshold of 10 voxels applied for display purposes; color bars indicate t-score scales. The spider plots (middle panels) show mean task-related effects, parameterized as $\beta$ weights (contrast estimates) across 7 canonical systems, where DA: dorsal attention; FP: cognitive (frontoparietal) control; DMN: default-mode network; LIM: (para)limbic; VIS: visual; SM: somatomotor; SAL: salience (ventral attention); ***, $p_{\mathrm{FDR}}<0.01 ; * *, p_{\mathrm{FDR}}<0.05 ; *$, uncorrected $p<0.05$. The upper and lower right-sided panels show task-related effects ( $\beta$ weights) stratified along the principal gradient, which depicts a continuous coordinate system running from unimodal (dark blue) areas at one end, to highorder transmodal (sienna) regions at the other end; its left lateral and midline views are provided in the middle of each plot, using the same color scale as in curves of gradient-stratified task effects. The gradient was discretized into 20 consecutive, equally-sized bins ( $x$ axis), with task-related signal ( $\beta$ weights; $y$ axis) computed per bin; shaded areas refer to $95 \%$ confidence intervals of mean effects at each bin; *, $p_{\mathrm{FDR}}<0.05 ; \nabla$, uncorrected $p<0.05$.

\section{Figure 2. Language fMRI: group comparisons}

The figure shows group comparisons for verbal fluency fMRI (upper panels) and verb generation fMRI (lower panels). In brain renders for comparison of patients with FLE and controls, cold and warm colors refer to lower and higher task-related effects in patients; of note, increases in FLE exclusively mapped on areas undergoing task-related deactivation, and are thus to be interpreted as areas of impaired deactivation in FLE vs controls; for comparison of FLE and TLE, cold and warm color scales refer to lower and higher task-related effects in FLE 
medRxiv preprint doi: https://doi.org/10.1101/2021.02.19.21251501; this version posted February 23,2021 . The copyright holder for this preprint (which was not certified by peer review) is the author/funder, who has granted medRxiv a license to display the preprint in It is made available under a CC-BY-NC-ND 4.0 International license

relative to TLE. Group differences are shown at $\mathrm{p}<0.005$, with an extent threshold of 10 voxels applied for display purposes; color bars indicate corresponding t-score scales, MNI coordinates and statistical details for differences within prespecified regions of interest are provided in the Supplementary Material. The spider plots (middle panels) show Z-score analyses of task effects across 7 canonical systems (abbreviated as in Figure 1); across panels, black heptagons display effects in controls (Z-score $=0$, for each system), while effects in FLE and TLE are shown in dark red and orange lines and correspondingly colored asterisks, respectively; the dark asterisk in the verb generation spider plot highlights a difference between FLE and TLE; ***, $p_{\mathrm{FDR}}<0.01 ; * *, p_{\mathrm{FDR}}<0.05 ; *$, uncorrected $p<0.05$. The upper and lower right panels show taskrelated effects, plotted as Z-scores ( $y$ axis), stratified along the principal gradient, which was discretized into 20 consecutive, equally-sized bins ( $x$ axis). Effects in FLE and TLE are shown in dark red and orange lines and in correspondingly colored asterisks, respectively; in each group, shaded areas correspond to one standard deviation; black asterisks refer to direct comparison of FLE and TLE; for each symbol, irrespective of color: *, $p_{\mathrm{FDR}}<0.05 ; \nabla$, uncorrected $p<0.05$.

\section{Figure 3. Working memory fMRI: task effects in controls}

Across analytical scales, the upper, middle, and lower figure panels show task effects in controls for verbal working, 1-0Back visuo-spatial, and 2-1Back visuo-spatial working memory fMRI, respectively. Panels on the left show task-related activation (warm colors) and deactivation (cold colors) in controls, as derived from one-sample $t$-tests. Brain renders show maps at $\mathrm{p}<0.001$, with an extent threshold of 10 voxels applied for display purposes; color bars indicate t-score scales. The spider plots (middle panels) show mean task-related effects, parameterized as $\beta$ weights (contrast estimates) across 7 functional systems, where DA: dorsal attention; FP: cognitive (frontoparietal) control; DMN: default-mode network; LIM: limbic; VIS: visual; SM: somatomotor; SAL: salience (ventral attention); $* * *, p_{\mathrm{FDR}}<0.01$; **, $p_{\mathrm{FDR}}<0.05 ; *$, uncorrected $p<0.05$. The upper and lower right panels show task-related effects stratified along the principal gradient; its left lateral and midline views are provided in the middle of each plot, using the same color scale as in curves of gradient-stratified task effects. The gradient was discretized into 20 consecutive, equally-sized bins ( $x$ axis), with task-related signal ( $\beta$ weights; $y$ axis) computed per bin; shaded areas refer to $95 \%$ confidence intervals of mean effects at each bin; ${ }^{*}, p_{\mathrm{FDR}}<0.05 ; \nabla$, uncorrected $p<0.05$. 
medRxiv preprint doi: https://doi.org/10.1101/2021.02.19.21251501; this version posted February 23,2021 . The copyright holder for this preprint (which was not certified by peer review) is the author/funder, who has granted medRxiv a license to display the preprint in It is made available under a CC-BY-NC-ND 4.0 International license .

\section{Figure 4. Working memory fMRI: group comparisons}

The upper, middle, and lower figure panels show group comparisons for verbal, 1-0Back visuo-spatial, and 2-1Back visuo-spatial working memory fMRI, respectively. In brain renders (left-sided panels) for comparison of patients with FLE and controls, cold and warm colors refer to lower and higher task-related effects in patients; for comparison of FLE and TLE, cold and warm color scales refer to lower and higher task-related effects in FLE than in TLE. Group differences are shown at $\mathrm{p}<0.005$, with an extent threshold of 10 voxels applied for display purposes; color bars indicate corresponding t-score scales, MNI coordinates and statistical details for differences within prespecified regions of interest are provided in the Supplementary Material. The spider plots (middle panels) show Z-score analyses of task-related signal across 7 canonical networks (abbreviations as in Figure 3); across panels, black heptagons display effects in controls (Z-score=0, at each system), while effects in FLE and TLE are shown in dark red and orange lines and in correspondingly colored asterisks, respectively; ***, $p_{\mathrm{FDR}}<0.01 ; * *, p \mathrm{FDR}<0.05 ; *$, uncorrected $p<0.05$. The z-score for cognitive control task activity in FLE, 1-0Back visual working memory, is 0.62; for display purposes, however, the spider plot axes reach a maximum of $\mathrm{Z}=0.5$. The upper and lower right panels show task-related effects, plotted as Z-scores ( $y$ axis), stratified along the principal gradient, which was discretized into 20 consecutive, equally-sized bins ( $x$ axis). Effects in FLE and TLE are shown in dark red and orange lines and in correspondingly colored asterisks, respectively; in each group, shaded areas correspond to one standard deviation; black asterisks refer to direct comparison of FLE and TLE; for each symbol, irrespective of color: *, $p$ FDR $<0.05 ; \nabla$, uncorrected $p<0.05$. Statistical details are provided in the main text.

\section{Figure 5. Correlations of functional imaging measures with cognitive performance}

The brain renders and sections on the left display statistical maps of nonparametric multiple regression analyses probing associations between language fMRI (verb generation) and naming scores (upper panel), and between working memory fMRI (verbal task) and digit span scores (lower panels). Cold/warm color scales refer to negative/positive associations, respectively. Maps are shown at $\mathrm{p}<0.005$, with an extent threshold of 10 voxels applied for display purposes; color bars indicate corresponding t-score scales. ^ Scatterplots highlight data distribution for the peak voxel within areas highlighted with a black circle; for illustration 
medRxiv preprint doi: https://doi.org/10.1101/2021.02.19.21251501; this version posted February 23,2021 . The copyright holder for this preprint (which was not certified by peer review) is the author/funder, who has granted medRxiv a license to display the preprint in

It is made available under a CC-BY-NC-ND 4.0 International license

purposes, we used age- and sex-adjusted (residualized) parameter estimates $(\beta)$ as measures of task effect. MNI coordinates and exact $p$-values are provided in the Supplementary Material. The spider plots (middle panels) and gradient plots (right-sided panels) show correlation coefficients for associations between cognitive measures (naming/digit span) and task effects (verb generation/verbal working memory) across each canonical system or each gradient bin. Example scatterplots are provided to highlight data distribution for correlations at the level of one given system or one given bin; for analyses of systems: ***, $p_{\mathrm{FDR}}<0.01$; **, $p_{\mathrm{FDR}}<0.05$; *, uncorrected $p<0.05$; for analyses along the gradient: *, $p_{\mathrm{FDR}}<0.05 ; \nabla$, uncorrected $p<0.05$.

\section{Figure 6. Correlations of functional imaging measures with clinical variables in FLE}

The brain sections on the left show statistical maps of nonparametric multiple regressions probing associations between language or working memory fMRI and epilepsy duration in FLE. For language (upper panels), we show positive associations between duration of epilepsy and task effects during verb generation, where significant voxels (right posterior temporal/angular ROI, $p_{\text {FWE }}<0.05$ within ROI; highlighted in black circle) map on areas undergoing task related deactivation; a positive association (warm color) indicates reduced deactivation with longer duration of disease. For working memory (lower panels), we show areas of negative associations between frontoparietal activation and disease duration with cold colors. Maps are shown at $\mathrm{p}<0.005$, with an extent threshold of 10 voxels applied for display purposes; color bars indicate t-score scales. ${ }^{\wedge}$ Scatterplots highlight data distribution for the peak voxel within areas highlighted with a black circle; for illustration purposes, we used ageand sex-adjusted (residualized) parameter estimates $(\beta)$ as measures of task effect. MNI coordinates and exact $p$-values are provided in the Supplementary Material. The spider plots (middle panels) and gradient plots (right-sided panels) show correlation coefficients for associations between epilepsy duration and task effects for verbal fluency fMRI, and between age at onset and verbal working memory fMRI, across each canonical system or gradient bin. Example scatterplots are provided to highlight data distribution for correlations at the level of one given system or one given bin; for analyses of systems: ***, $p_{\mathrm{FDR}}<0.01$; **, $p \mathrm{FDR}<0.05$; *, uncorrected $p<0.05$; for analyses along the gradient $*, p_{\mathrm{FDR}}<0.05 ; \nabla$, uncorrected $p<0.05$.

\section{REFERENCES}


medRxiv preprint doi: https://doi.org/10.1101/2021.02.19.21251501; this version posted February 23, 2021. The copyright holder for this preprint (which was not certified by peer review) is the author/funder, who has granted medRxiv a license to display the preprint in It is made available under a CC-BY-NC-ND 4.0 International license .

1. Jobst BC, Siegel AM, Thadani VM, Roberts DW, Rhodes HC, Williamson PD. Intractable seizures of frontal lobe origin: clinical characteristics, localizing signs, and results of surgery. Epilepsia. 2000;41(9):1139-1152.

2. O'Muircheartaigh J, Richardson MP. Epilepsy and the frontal lobes. Cortex; a journal devoted to the study of the nervous system and behavior. Feb 2012;48(2):144-55. doi:10.1016/j.cortex.2011.11.012

3. Lee JJ, Lee SK, Lee SY, et al. Frontal lobe epilepsy: clinical characteristics, surgical outcomes and diagnostic modalities. Seizure. Sep 2008;17(6):514-23. doi:10.1016/j.seizure.2008.01.007

4. Lin JJ, Mula M, Hermann BP. Uncovering the neurobehavioural comorbidities of epilepsy over the lifespan. Lancet. Sep 29 2012;380(9848):1180-92. doi:10.1016/s01406736(12)61455-X

5. Elger CE, Helmstaedter C, Kurthen M. Chronic epilepsy and cognition. Lancet Neurol. Nov 2004;3(11):663-72. doi:10.1016/s1474-4422(04)00906-8

6. Stretton J, Thompson PJ. Frontal lobe function in temporal lobe epilepsy. Epilepsy Res. Jan 2012;98(1):1-13. doi:10.1016/j.eplepsyres.2011.10.009

7. Bell B, Lin JJ, Seidenberg M, Hermann B. The neurobiology of cognitive disorders in temporal lobe epilepsy. Review. Nat Rev Neurol. Mar 2011;7(3):154-64. doi:10.1038/nrneurol.2011.3

8. Upton D, Thompson PJ. General neuropsychological characteristics of frontal lobe epilepsy. Epilepsy research. Mar 1996;23(2):169-77.

9. Helmstaedter C, Kemper B, Elger CE. Neuropsychological aspects of frontal lobe epilepsy. Neuropsychologia. May 1996;34(5):399-406. doi:0028-3932(95)00121-2 [pii]

10. Patrikelis P, Angelakis E, Gatzonis S. Neurocognitive and behavioral functioning in frontal lobe epilepsy: a review. Epilepsy \& behavior : E\&B. Jan 2009;14(1):19-26. doi:10.1016/j.yebeh.2008.09.013

11. Risse GL. Cognitive outcomes in patients with frontal lobe epilepsy. Epilepsia. 2006;47 Suppl 2:87-9. doi:10.1111/j.1528-1167.2006.00699.x

12. Centeno M, Thompson PJ, Koepp MJ, Helmstaedter C, Duncan JS. Memory in frontal lobe epilepsy. Epilepsy research. Oct 2010;91(2-3):123-32. doi:10.1016/j.eplepsyres.2010.07.017 13. Exner C, Boucsein K, Lange C, et al. Neuropsychological performance in frontal lobe epilepsy. Seizure. Jan 2002;11(1):20-32. doi:10.1053/seiz.2001.0572 
medRxiv preprint doi: https://doi.org/10.1101/2021.02.19.21251501; this version posted February 23,2021 . The copyright holder for this preprint (which was not certified by peer review) is the author/funder, who has granted medRxiv a license to display the preprint in It is made available under a CC-BY-NC-ND 4.0 International license .

14. Patrikelis P, Gatzonis S, Siatouni A, et al. Preoperative neuropsychological presentation of patients with refractory frontal lobe epilepsy. Acta Neurochir (Wien). Jun 2016;158(6):113950. doi:10.1007/s00701-016-2786-4

15. McDonald CR, Delis DC, Norman MA, Wetter SR, Tecoma ES, Iragui VJ. Response inhibition and set shifting in patients with frontal lobe epilepsy or temporal lobe epilepsy. Epilepsy Behav. Nov 2005;7(3):438-46. doi:10.1016/j.yebeh.2005.05.005

16. Metternich B, Buschmann F, Wagner K, Schulze-Bonhage A, Kriston L. Verbal fluency in focal epilepsy: a systematic review and meta-analysis. Neuropsychol Rev. Jun 2014;24(2):20018. doi:10.1007/s 11065-014-9255-8

17. Verche E, San Luis C, Hernandez S. Neuropsychology of frontal lobe epilepsy in children and adults: Systematic review and meta-analysis. Epilepsy Behav. Nov 2018;88:15-20. doi:10.1016/j.yebeh.2018.08.008

18. Stretton J, Winston G, Sidhu M, et al. Neural correlates of working memory in Temporal Lobe Epilepsy--an fMRI study. NeuroImage. Apr 15 2012;60(3):1696-703. doi:10.1016/j.neuroimage.2012.01.126

19. Stretton J, Winston GP, Sidhu M, et al. Disrupted segregation of working memory networks in temporal lobe epilepsy. Neuroimage Clin. 2013;2:273-81. doi:10.1016/j.nicl.2013.01.009

20. Thivard L, Hombrouck J, du Montcel ST, et al. Productive and perceptive language reorganization in temporal lobe epilepsy. Neuroimage. Feb 1 2005;24(3):841-51. doi:10.1016/j.neuroimage.2004.10.001

21. Berl MM, Zimmaro LA, Khan OI, et al. Characterization of atypical language activation patterns in focal epilepsy. Ann Neurol. Jan 2014;75(1):33-42. doi:10.1002/ana.24015

22. Trimmel K, van Graan AL, Caciagli L, et al. Left temporal lobe language network connectivity in temporal lobe epilepsy. Brain. Aug 1 2018;141(8):2406-2418. doi:10.1093/brain/awy164

23. He X, Bassett DS, Chaitanya G, Sperling MR, Kozlowski L, Tracy JI. Disrupted dynamic network reconfiguration of the language system in temporal lobe epilepsy. Brain. May 1 2018;141(5):1375-1389. doi:10.1093/brain/awy042

24. Stewart CC, Swanson SJ, Sabsevitz DS, Rozman ME, Janecek JK, Binder JR. Predictors of language lateralization in temporal lobe epilepsy. Neuropsychologia. Jul 2014;60:93-102. doi:10.1016/j.neuropsychologia.2014.05.021

25. Tailby C, Kowalczyk MA, Jackson GD. Cognitive impairment in epilepsy: the role of reduced network flexibility. Ann Clin Transl Neurol. Jan 2018;5(1):29-40. doi:10.1002/acn3.503 
medRxiv preprint doi: https://doi.org/10.1101/2021.02.19.21251501; this version posted February 23, 2021. The copyright holder for this preprint (which was not certified by peer review) is the author/funder, who has granted medRxiv a license to display the preprint in It is made available under a CC-BY-NC-ND 4.0 International license .

26. Weber B, Wellmer J, Reuber M, et al. Left hippocampal pathology is associated with atypical language lateralization in patients with focal epilepsy. Brain. Feb 2006;129(Pt 2):34651. doi:10.1093/brain/awh694

27. Nair S, Szaflarski JP. Neuroimaging of memory in frontal lobe epilepsy. Epilepsy Behav. Feb 2020;103(Pt A):106857. doi:10.1016/j.yebeh.2019.106857

28. Braakman HM, Vaessen MJ, Jansen JF, et al. Frontal lobe connectivity and cognitive impairment in pediatric frontal lobe epilepsy. Epilepsia. Mar 2013;54(3):446-54. doi:10.1111/epi.12044

29. Centeno M, Vollmar C, O'Muircheartaigh J, et al. Memory in frontal lobe epilepsy: an fMRI study. Epilepsia. Oct 2012;53(10):1756-64. doi:10.1111/j.1528-1167.2012.03570.x

30. Woodward KE, Gaxiola-Valdez I, Mainprize D, Grossi M, Goodyear BG, Federico P. Recent seizure activity alters motor organization in frontal lobe epilepsy as revealed by taskbased fMRI. Epilepsy Res. Oct 2014;108(8):1286-98. doi:10.1016/j.eplepsyres.2014.06.015 31. Owen AM, McMillan KM, Laird AR, Bullmore E. N-back working memory paradigm: a meta-analysis of normative functional neuroimaging studies. Hum Brain Mapp. May 2005;25(1):46-59. doi:10.1002/hbm.20131

32. Costafreda SG, Fu CH, Lee L, Everitt B, Brammer MJ, David AS. A systematic review and quantitative appraisal of fMRI studies of verbal fluency: role of the left inferior frontal gyrus. Hum Brain Mapp. Oct 2006;27(10):799-810. doi:10.1002/hbm.20221

33. Anticevic A, Cole MW, Murray JD, Corlett PR, Wang XJ, Krystal JH. The role of default network deactivation in cognition and disease. Trends Cogn Sci. Dec 2012;16(12):584-92. doi:10.1016/j.tics.2012.10.008

34. Cocchi L, Zalesky A, Fornito A, Mattingley JB. Dynamic cooperation and competition between brain systems during cognitive control. Trends Cogn Sci. Oct 2013;17(10):493-501. doi:10.1016/j.tics.2013.08.006

35. Murphy AC, Bertolero MA, Papadopoulos L, Lydon-Staley DM, Bassett DS. Multimodal network dynamics underpinning working memory. Nat Commun. Jun 15 2020;11(1):3035. doi:10.1038/s41467-020-15541-0

36. Yeo BT, Krienen FM, Sepulcre J, et al. The organization of the human cerebral cortex estimated by intrinsic functional connectivity. J Neurophysiol. Sep 2011;106(3):1125-65. doi:10.1152/jn.00338.2011

37. Margulies DS, Ghosh SS, Goulas A, et al. Situating the default-mode network along a principal gradient of macroscale cortical organization. Proc Natl Acad Sci U S A. Nov 1 2016;113(44):12574-12579. doi:10.1073/pnas.1608282113 
medRxiv preprint doi: https://doi.org/10.1101/2021.02.19.21251501; this version posted February 23,2021 . The copyright holder for this preprint (which was not certified by peer review) is the author/funder, who has granted medRxiv a license to display the preprint in It is made available under a CC-BY-NC-ND 4.0 International license .

38. Huntenburg JM, Bazin PL, Margulies DS. Large-Scale Gradients in Human Cortical Organization. Trends Cogn Sci. Jan 2018;22(1):21-31. doi:10.1016/j.tics.2017.11.002

39. Mesulam MM. From sensation to cognition. Brain. Jun 1998;121 ( Pt 6):1013-52.

40. Murphy C, Jefferies E, Rueschemeyer SA, et al. Distant from input: Evidence of regions within the default mode network supporting perceptually-decoupled and conceptually-guided cognition. Neuroimage. May 1 2018;171:393-401. doi:10.1016/j.neuroimage.2018.01.017

41. Sormaz M, Murphy C, Wang HT, et al. Default mode network can support the level of detail in experience during active task states. Proc Natl Acad Sci U S A. Sep 11 2018;115(37):9318-9323. doi:10.1073/pnas.1721259115

42. Turnbull A, Karapanagiotidis T, Wang HT, et al. Reductions in task positive neural systems occur with the passage of time and are associated with changes in ongoing thought. Sci Rep. Jun 18 2020;10(1):9912. doi:10.1038/s41598-020-66698-Z

43. Li Q, Tavakol S, Royer J, et al. Human brain function during pattern separation follows hippocampal and neocortical connectivity gradients. bioRxiv. 2020:2020.06.22.165290. doi:10.1101/2020.06.22.165290

44. Wandschneider B, Stretton J, Sidhu M, et al. Levetiracetam reduces abnormal network activations in temporal lobe epilepsy. Neurology. Oct 21 2014;83(17):1508-12. doi:10.1212/wnl.0000000000000910

45. Wandschneider B, Burdett J, Townsend L, et al. Effect of topiramate and zonisamide on fMRI cognitive networks. Neurology. Mar $21 \quad$ 2017;88(12):1165-1171. doi:10.1212/wnl.0000000000003736

46. Ratcliffe C, Wandschneider B, Baxendale S, Thompson P, Koepp MJ, Caciagli L. Cognitive Function in Genetic Generalized Epilepsies: Insights From Neuropsychology and Neuroimaging. Front Neurol. 2020;11:144. doi:10.3389/fneur.2020.00144

47. Vollmar C, O'Muircheartaigh J, Barker GJ, et al. Motor system hyperconnectivity in juvenile myoclonic epilepsy: a cognitive functional magnetic resonance imaging study. Brain. Jun 2011;134(Pt 6):1710-9. doi:10.1093/brain/awr098

48. Bonelli SB, Powell R, Thompson PJ, et al. Hippocampal activation correlates with visual confrontation naming: fMRI findings in controls and patients with temporal lobe epilepsy. Epilepsy research. Aug 2011;95(3):246-54. doi:10.1016/j.eplepsyres.2011.04.007

49. Powell HW, Parker GJ, Alexander DC, et al. Hemispheric asymmetries in language-related pathways: a combined functional MRI and tractography study. Neuroimage. Aug 1 2006;32(1):388-99. doi:10.1016/j.neuroimage.2006.03.011 
medRxiv preprint doi: https://doi.org/10.1101/2021.02.19.21251501; this version posted February 23, 2021. The copyright holder for this preprint (which was not certified by peer review) is the author/funder, who has granted medRxiv a license to display the preprint in It is made available under a CC-BY-NC-ND 4.0 International license .

50. Benjamini Y, Hochberg Y. Controlling the false discovery rate: a practical and powerful approach to multiple testing. J Royal Stat Soc. 1995;57(1):289-300.

51. Caciagli L, Wandschneider B, Xiao F, et al. Abnormal hippocampal structure and function in juvenile myoclonic epilepsy and unaffected siblings. Brain. Sep 1 2019;142(9):2670-2687. doi:10.1093/brain/awz215

52. Power JD, Barnes KA, Snyder AZ, Schlaggar BL, Petersen SE. Spurious but systematic correlations in functional connectivity MRI networks arise from subject motion. Neuroimage. 2012;59(3):2142-52. doi:10.1016/j.neuroimage.2011.10.018

53. Nichols TE, Holmes AP. Nonparametric permutation tests for functional neuroimaging: a primer with examples. Hum Brain Mapp. Jan 2002;15(1):1-25. doi:10.1002/hbm.1058

54. Worsley KJ, Taylor JE, Tomaiuolo F, Lerch J. Unified univariate and multivariate random field theory. Neuroimage. 2004;23 Suppl 1:S189-95.

55. Schaefer A, Kong R, Gordon EM, et al. Local-Global Parcellation of the Human Cerebral Cortex from Intrinsic Functional Connectivity MRI. Cereb Cortex. Sep 1 2018;28(9):30953114. doi:10.1093/cercor/bhx179

56. Larivière S, Weng Y, Vos de Wael R, et al. Functional connectome contractions in temporal lobe epilepsy: Microstructural underpinnings and predictors of surgical outcome. Epilepsia. Jun 2020;61(6):1221-1233. doi:10.1111/epi.16540

57. Paquola C, Vos De Wael R, Wagstyl K, et al. Microstructural and functional gradients are increasingly dissociated in transmodal cortices. PLoS Biol. May 2019;17(5):e3000284. doi:10.1371/journal.pbio.3000284

58. Vos de Wael R, Benkarim O, Paquola C, et al. BrainSpace: a toolbox for the analysis of macroscale gradients in neuroimaging and connectomics datasets. Commun Biol. Mar 5 2020;3(1):103. doi:10.1038/s42003-020-0794-7

59. Glasser MF, Sotiropoulos SN, Wilson JA, et al. The minimal preprocessing pipelines for the Human Connectome Project. Neuroimage. Oct 15 2013;80:105-24. doi:10.1016/j.neuroimage.2013.04.127

60. Lowe AJ, Paquola C, Vos de Wael R, et al. Targeting age-related differences in brain and cognition with multimodal imaging and connectome topography profiling. Hum Brain Mapp. Dec 15 2019;40(18):5213-5230. doi:10.1002/hbm.24767

61. He X, Chaitanya G, Asma B, et al. Disrupted basal ganglia-thalamocortical loops in focal to bilateral tonic-clonic seizures. Brain. Jan 1 2020;143(1):175-190. doi:10.1093/brain/awz361 
medRxiv preprint doi: https://doi.org/10.1101/2021.02.19.21251501; this version posted February 23, 2021. The copyright holder for this preprint (which was not certified by peer review) is the author/funder, who has granted medRxiv a license to display the preprint in It is made available under a CC-BY-NC-ND 4.0 International license .

62. Weng Y, Larivière S, Caciagli L, et al. Macroscale and microcircuit dissociation of focal and generalized human epilepsies. Commun Biol. May 18 2020;3(1):244. doi:10.1038/s42003020-0958-5

63. Bassett DS, Nelson BG, Mueller BA, Camchong J, Lim KO. Altered resting state complexity in schizophrenia. Neuroimage. Feb 1 2012;59(3):2196-207. doi:10.1016/j.neuroimage.2011.10.002

64. Poldrack RA, Fletcher PC, Henson RN, Worsley KJ, Brett M, Nichols TE. Guidelines for reporting an fMRI study. Neuroimage. Apr 1 2008;40(2):409-414. doi:10.1016/j.neuroimage.2007.11.048

65. Krienen FM, Yeo BT, Buckner RL. Reconfigurable task-dependent functional coupling modes cluster around a core functional architecture. Philos Trans R Soc Lond B Biol Sci. Oct 5 2014;369(1653)doi:10.1098/rstb.2013.0526

66. Haak KV, Marquand AF, Beckmann CF. Connectopic mapping with resting-state fMRI. Neuroimage. Apr 15 2018;170:83-94. doi:10.1016/j.neuroimage.2017.06.075

67. Shao Z, Janse E, Visser K, Meyer AS. What do verbal fluency tasks measure? Predictors of verbal fluency performance in older adults. Frontiers in psychology. 2014;5:772. doi:10.3389/fpsyg.2014.00772

68. Binder JR, Desai RH, Graves WW, Conant LL. Where is the semantic system? A critical review and meta-analysis of 120 functional neuroimaging studies. Cereb Cortex. Dec 2009;19(12):2767-96. doi:10.1093/cercor/bhp055

69. Price CJ. A review and synthesis of the first 20 years of PET and fMRI studies of heard speech, spoken language and reading. NeuroImage. Aug 15 2012;62(2):816-47. doi:10.1016/j.neuroimage.2012.04.062

70. Duke ES, Tesfaye M, Berl MM, et al. The effect of seizure focus on regional language processing areas. Epilepsia. Jun 2012;53(6):1044-50. doi:10.1111/j.1528-1167.2012.03490.x 71. Anderson DP, Harvey AS, Saling MM, et al. FMRI lateralization of expressive language in children with cerebral lesions. Epilepsia. Jun 2006;47(6):998-1008. doi:10.1111/j.15281167.2006.00572.x

72. Saling MM. Verbal memory in mesial temporal lobe epilepsy: beyond material specificity. Brain. Mar 2009;132(Pt 3):570-82. doi:10.1093/brain/awp012

73. Kaestner E, Reyes A, Macari AC, et al. Identifying the neural basis of a language-impaired phenotype of temporal lobe epilepsy. Epilepsia. Aug 2019;60(8):1627-1638. doi:10.1111/epi.16283 
medRxiv preprint doi: https://doi.org/10.1101/2021.02.19.21251501; this version posted February 23,2021 . The copyright holder for this preprint (which was not certified by peer review) is the author/funder, who has granted medRxiv a license to display the preprint in It is made available under a CC-BY-NC-ND 4.0 International license .

74. Reyes A, Kaestner E, Bahrami N, et al. Cognitive phenotypes in temporal lobe epilepsy are associated with distinct patterns of white matter network abnormalities. Neurology. Apr 23 2019;92(17):e1957-e1968. doi:10.1212/wnl.0000000000007370

75. Bonini F, McGonigal A, Trebuchon A, et al. Frontal lobe seizures: from clinical semiology to localization. Epilepsia. Feb 2014;55(2):264-77. doi:10.1111/epi.12490

76. Vigneau M, Beaucousin V, Herve PY, et al. What is right-hemisphere contribution to phonological, lexico-semantic, and sentence processing? Insights from a meta-analysis. Neuroimage. Jan 1 2011;54(1):577-93. doi:10.1016/j.neuroimage.2010.07.036

77. Bonelli SB, Thompson PJ, Yogarajah M, et al. Imaging language networks before and after anterior temporal lobe resection: results of a longitudinal fMRI study. Epilepsia. Apr 2012;53(4):639-50. doi:10.1111/j.1528-1167.2012.03433.x

78. Pravata E, Sestieri C, Mantini D, et al. Functional connectivity MR imaging of the language network in patients with drug-resistant epilepsy. AJNR Am $J$ Neuroradiol. Mar 2011;32(3):532-40. doi:10.3174/ajnr.A2311

79. Noonan KA, Jefferies E, Visser M, Lambon Ralph MA. Going beyond inferior prefrontal involvement in semantic control: evidence for the additional contribution of dorsal angular gyrus and posterior middle temporal cortex. J Cogn Neurosci. Nov 2013;25(11):1824-50. doi:10.1162/jocn_a_00442

80. Price CJ, Devlin JT, Moore CJ, Morton C, Laird AR. Meta-analyses of object naming: effect of baseline. Hum Brain Mapp. May 2005;25(1):70-82. doi:10.1002/hbm.20132

81. Rottschy C, Langner R, Dogan I, et al. Modelling neural correlates of working memory: a coordinate-based meta-analysis. Neuroimage. Mar 2012;60(1):830-46. doi:10.1016/j.neuroimage.2011.11.050

82. Pessoa L, Gutierrez E, Bandettini P, Ungerleider L. Neural correlates of visual working memory: fMRI amplitude predicts task performance. Neuron. Aug 29 2002;35(5):975-87. doi:10.1016/s0896-6273(02)00817-6

83. Palva JM, Monto S, Kulashekhar S, Palva S. Neuronal synchrony reveals working memory networks and predicts individual memory capacity. Proc Natl Acad Sci U S A. Apr 20 2010;107(16):7580-5. doi:10.1073/pnas.0913113107

84. Greicius MD, Krasnow B, Reiss AL, Menon V. Functional connectivity in the resting brain: a network analysis of the default mode hypothesis. Proc Natl Acad Sci U S A. Jan 7 2003;100(1):253-8. doi:10.1073/pnas.0135058100 
medRxiv preprint doi: https://doi.org/10.1101/2021.02.19.21251501; this version posted February 23,2021 . The copyright holder for this preprint (which was not certified by peer review) is the author/funder, who has granted medRxiv a license to display the preprint in It is made available under a CC-BY-NC-ND 4.0 International license .

85. Buckner RL, Andrews-Hanna JR, Schacter DL. The brain's default network: anatomy, function, and relevance to disease. Annals of the New York Academy of Sciences. Mar 2008;1124:1-38. doi:10.1196/annals.1440.011

86. Andrews-Hanna JR, Smallwood J, Spreng RN. The default network and self-generated thought: component processes, dynamic control, and clinical relevance. Ann N Y Acad Sci. May 2014;1316:29-52. doi:10.1111/nyas. 12360

87. Kelly AM, Uddin LQ, Biswal BB, Castellanos FX, Milham MP. Competition between functional brain networks mediates behavioral variability. Neuroimage. Jan 1 2008;39(1):52737. doi:10.1016/j.neuroimage.2007.08.008

88. Li M, Dahmani L, Wang D, et al. Co-activation patterns across multiple tasks reveal robust anti-correlated functional networks. Neuroimage. Dec 26 2020;227:117680. doi:10.1016/j.neuroimage.2020.117680

89. Kennedy DP, Redcay E, Courchesne E. Failing to deactivate: resting functional abnormalities in autism. Proc Natl Acad Sci U S A. May 23 2006;103(21):8275-80. doi:10.1073/pnas.0600674103

90. Broyd SJ, Demanuele C, Debener S, Helps SK, James CJ, Sonuga-Barke EJ. Default-mode brain dysfunction in mental disorders: a systematic review. Neurosci Biobehav Rev. Mar 2009;33(3):279-96. doi:10.1016/j.neubiorev.2008.09.002

91. Whitfield-Gabrieli S, Thermenos HW, Milanovic S, et al. Hyperactivity and hyperconnectivity of the default network in schizophrenia and in first-degree relatives of persons with schizophrenia. Proc Natl Acad Sci U S A. Jan 27 2009;106(4):1279-84. doi:0809141106 [pii] 10.1073/pnas.0809141106

92. Garrity AG, Pearlson GD, McKiernan K, Lloyd D, Kiehl KA, Calhoun VD. Aberrant "default mode" functional connectivity in schizophrenia. Am $J$ Psychiatry. Mar 2007;164(3):450-7. doi:10.1176/ajp.2007.164.3.450

93. Spencer MD, Chura LR, Holt RJ, et al. Failure to deactivate the default mode network indicates a possible endophenotype of autism. Molecular autism. Dec 03 2012;3(1):15. doi:10.1186/2040-2392-3-15

94. Oyegbile TO, VanMeter JW, Motamedi GK, Bell WL, Gaillard WD, Hermann BP. Default mode network deactivation in pediatric temporal lobe epilepsy: Relationship to a working memory task and executive function tests. Epilepsy Behav. May 2019;94:124-130. doi:10.1016/j.yebeh.2019.02.031 
medRxiv preprint doi: https://doi.org/10.1101/2021.02.19.21251501; this version posted February 23,2021 . The copyright holder for this preprint (which was not certified by peer review) is the author/funder, who has granted medRxiv a license to display the preprint in It is made available under a CC-BY-NC-ND 4.0 International license .

95. Xiao F, Caciagli L, Wandschneider B, et al. Effects of carbamazepine and lamotrigine on functional magnetic resonance imaging cognitive networks. Epilepsia. Jul 2018;59(7):13621371. doi:10.1111/epi.14448

96. Hermann B, Seidenberg M, Jones J. The neurobehavioural comorbidities of epilepsy: can a natural history be developed?. Lancet Neurol. Feb 2008;7(2):151-60. doi:10.1016/s14744422(08)70018-8

97. Berg AT, Zelko FA, Levy SR, Testa FM. Age at onset of epilepsy, pharmacoresistance, and cognitive outcomes: a prospective cohort study. Neurology. Sep 25 2012;79(13):1384-91. doi:10.1212/WNL.0b013e31826c1b55

98. Rayner G, Jackson GD, Wilson SJ. Mechanisms of memory impairment in epilepsy depend on age at disease onset. Neurology. Oct 18 2016;87(16):1642-1649. doi:10.1212/wnl.0000000000003231

99. Kaaden S, Helmstaedter C. Age at onset of epilepsy as a determinant of intellectual impairment in temporal lobe epilepsy. Epilepsy Behav. Jun 2009;15(2):213-7. doi:10.1016/j.yebeh.2009.03.027

100. Hermann B, Seidenberg M, Bell B, et al. The neurodevelopmental impact of childhoodonset temporal lobe epilepsy on brain structure and function. Epilepsia. Sep 2002;43(9):106271.

101. Lee CY, Tabesh A, Benitez A, Helpern JA, Jensen JH, Bonilha L. Microstructural integrity of early-versus late-myelinating white matter tracts in medial temporal lobe epilepsy. Epilepsia. Oct 2013;54(10):1801-9. doi:10.1111/epi.12353

102. Darki F, Klingberg T. The role of fronto-parietal and fronto-striatal networks in the development of working memory: a longitudinal study. Cereb Cortex. Jun 2015;25(6):158795. doi:10.1093/cercor/bht352

103. Tamnes CK, Walhovd KB, Grydeland $\mathrm{H}$, et al. Longitudinal working memory development is related to structural maturation of frontal and parietal cortices. $J$ Cogn Neurosci. Oct 2013;25(10):1611-23. doi:10.1162/jocn_a_00434

104. Turner GR, Spreng RN. Prefrontal Engagement and Reduced Default Network Suppression Co-occur and Are Dynamically Coupled in Older Adults: The Default-Executive Coupling Hypothesis of Aging. $J$ Cogn Neurosci. Dec 2015;27(12):2462-76. doi:10.1162/jocn_a_00869

105. Rieck JR, Rodrigue KM, Boylan MA, Kennedy KM. Age-related reduction of BOLD modulation to cognitive difficulty predicts poorer task accuracy and poorer fluid reasoning ability. Neuroimage. Feb 15 2017;147:262-271. doi:10.1016/j.neuroimage.2016.12.022 
medRxiv preprint doi: https://doi.org/10.1101/2021.02.19.21251501; this version posted February 23,2021 . The copyright holder for this preprint (which was not certified by peer review) is the author/funder, who has granted medRxiv a license to display the preprint in It is made available under a CC-BY-NC-ND 4.0 International license .

106. Liu RS, Lemieux L, Bell GS, et al. Progressive neocortical damage in epilepsy. Ann Neurol. Mar 2003;53(3):312-24.

107. Bernhardt BC, Worsley KJ, Kim H, Evans AC, Bernasconi A, Bernasconi N. Longitudinal and cross-sectional analysis of atrophy in pharmacoresistant temporal lobe epilepsy. Neurology. May 19 2009;72(20):1747-54. doi:10.1212/01.wnl.0000345969.57574.f5 108. Caciagli L, Bernasconi A, Wiebe S, Koepp MJ, Bernasconi N, Bernhardt BC. A metaanalysis on progressive atrophy in intractable temporal lobe epilepsy: Time is brain? Neurology. Aug 1 2017;89(5):506-516. doi:10.1212/wnl.0000000000004176

109. Galovic M, van Dooren VQH, Postma T, et al. Progressive Cortical Thinning in Patients With Focal Epilepsy. JAMA Neurol. Jul 1 2019;76(10):1230-9. doi:10.1001/jamaneurol.2019.1708

110. Simasathien T, Vadera S, Najm I, Gupta A, Bingaman W, Jehi L. Improved outcomes with earlier surgery for intractable frontal lobe epilepsy. Ann Neurol. May 2013;73(5):646-54. doi:10.1002/ana.23862

111. Szaflarski JP, Gloss D, Binder JR, et al. Practice guideline summary: Use of fMRI in the presurgical evaluation of patients with epilepsy: Report of the Guideline Development, Dissemination, and Implementation Subcommittee of the American Academy of Neurology. Neurology. Jan 24 2017;88(4):395-402. doi:10.1212/wnl.0000000000003532

112. Black DF, Vachha B, Mian A, et al. American Society of Functional NeuroradiologyRecommended fMRI Paradigm Algorithms for Presurgical Language Assessment. AJNR Am J Neuroradiol. Oct 2017;38(10):E65-e73. doi:10.3174/ajnr.A5345

113. Caciagli L, Xiao F, Wandschneider B, Koepp MJ. Imaging Biomarkers of AntiEpileptic Drug Action: Insights from Magnetic Resonance Imaging. Curr Pharm Des. 2017;23(37):5727-5739. doi:10.2174/1381612823666170809113636

114. Mitchell SM, Lange S, Brus H. Gendered citation patterns in international relations journals. International Studies Perspectives. 2013;14(4):485-492.

115. Maliniak D, Powers R, Walter BF. The gender citation gap in international relations. International Organization. 2013;67(4):889-922.

116. Caplar N, Tacchella S, Birrer S. Quantitative evaluation of gender bias in astronomical publications from citation counts. Nature Astronomy. 2017;1(6):1-5.

117. Dion ML, Sumner JL, Mitchell SM. Gendered citation patterns across political science and social science methodology fields. Political Analysis. 2018;26(3):312-327. 
medRxiv preprint doi: https://doi.org/10.1101/2021.02.19.21251501; this version posted February 23, 2021. The copyright holder for this preprint (which was not certified by peer review) is the author/funder, who has granted medRxiv a license to display the preprint in It is made available under a CC-BY-NC-ND 4.0 International license.

118. Dworkin JD, Linn KA, Teich EG, Zurn P, Shinohara RT, Bassett DS. The extent and drivers of gender imbalance in neuroscience reference lists. Nat Neurosci. Aug 2020;23(8):918-926. doi:10.1038/s41593-020-0658-y

119. Zhou D, Cornblath EJ, Stiso J, et al. Gender Diversity Statement and Code Note-Book v1. 0. Zenodo; 2020.

120. Ambekar A, Ward C, Mohammed J, Male S, Skiena S. Name-ethnicity classification from open sources. 49-58.

121. Sood G, Laohaprapanon S. Predicting race and ethnicity from the sequence of characters in a name. arXiv preprint arXiv:180502109. 2018; 


\section{Language fMRI}

\section{Verbal fluency - task effects in CTR}

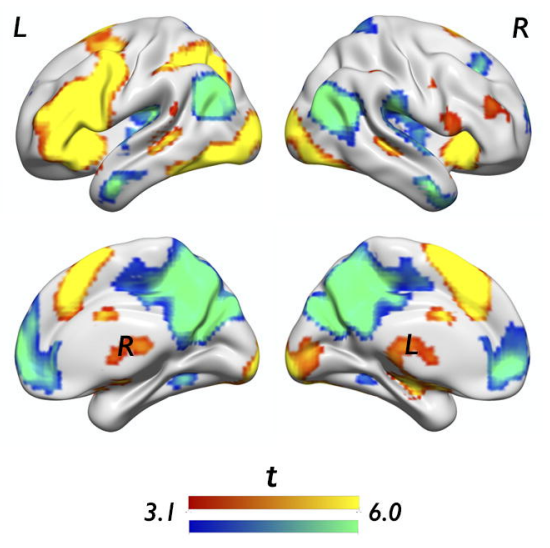

Voxel-based maps

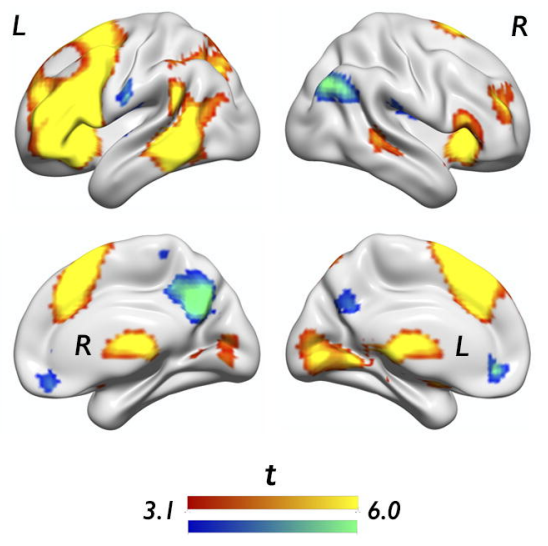

Voxel-based maps

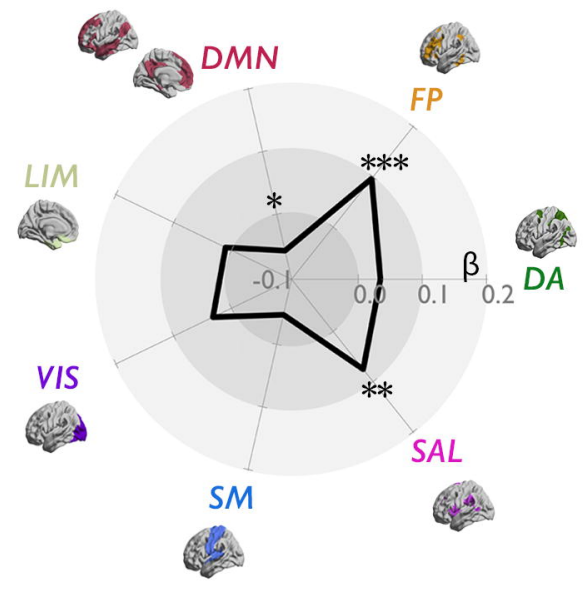

Task activity on systems

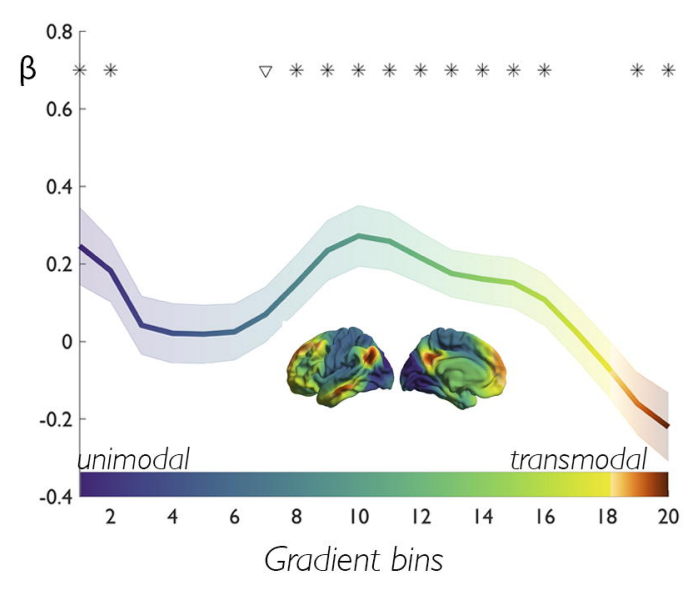

Task activity on gradient

Verb generation - task effects in CTR

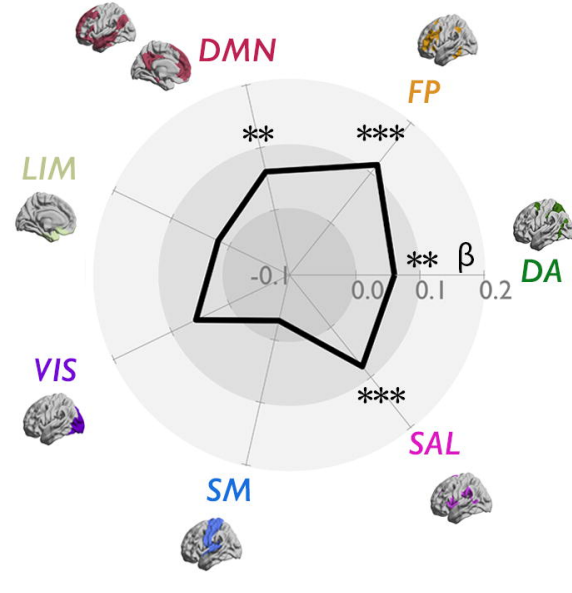

Task activity on systems

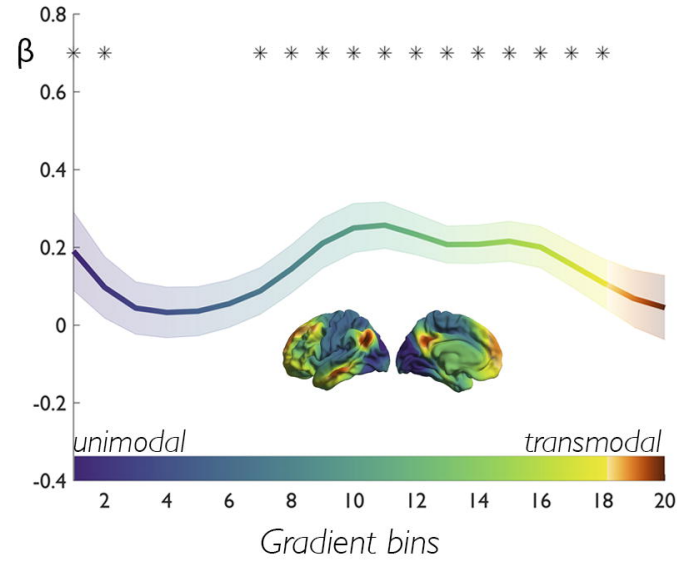

Task activity on gradient 


\section{Language fMRI}

\section{Verbal fluency - group comparisons}

FLE vs CTR
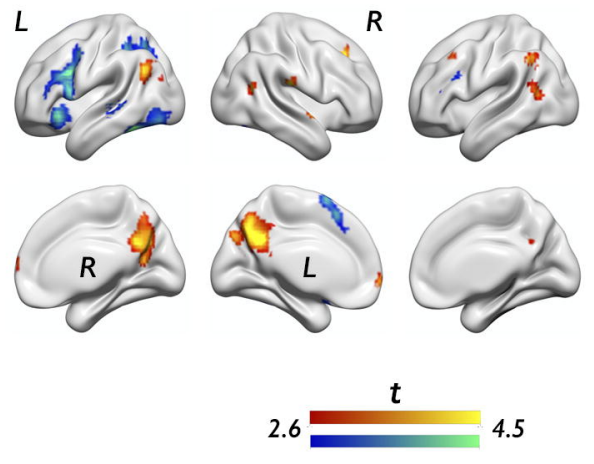

Voxel-based maps
- FLE $D M N$

LIM

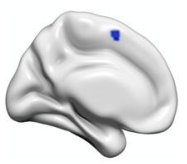

VIS

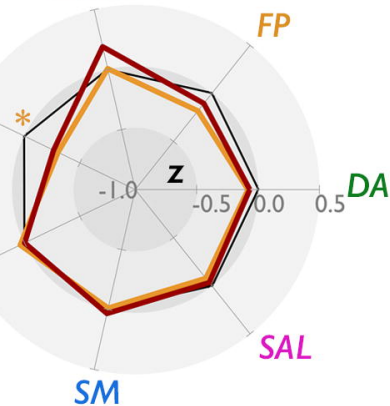

Task activity on systems

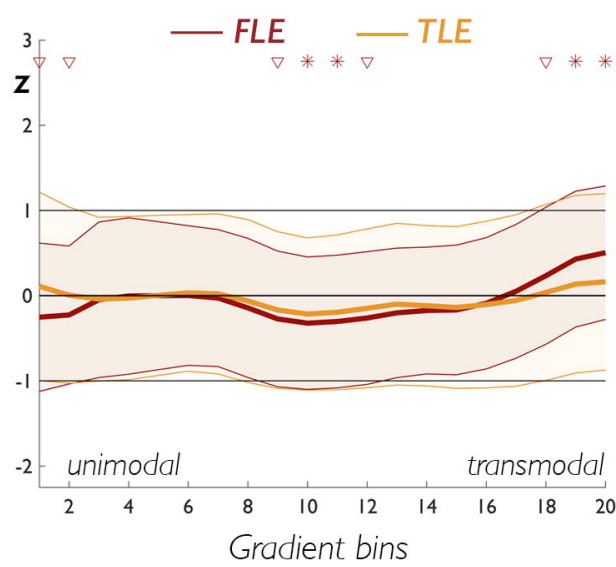

Task activity on gradient

Verb generation - group comparisons

FLE vs CTR

$L$
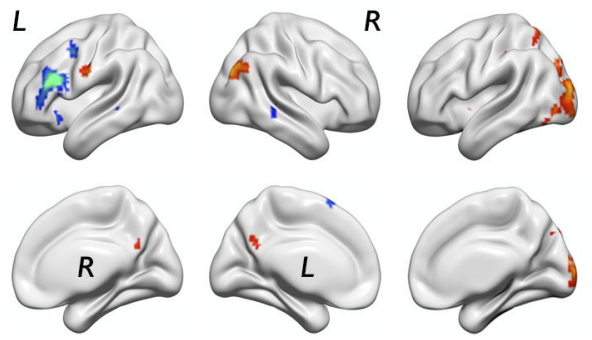

$t$

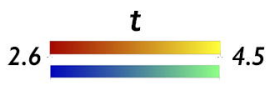

Voxel-based maps

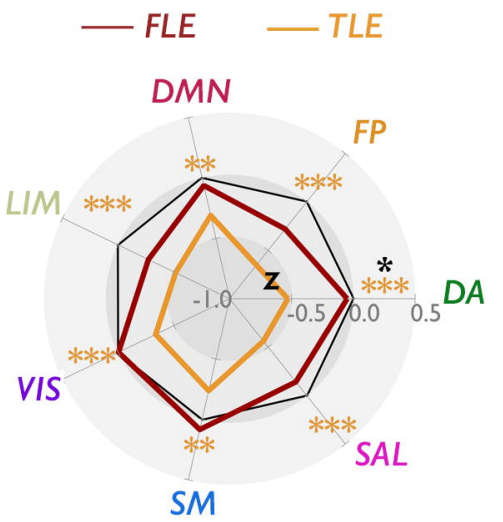

Task activity on systems

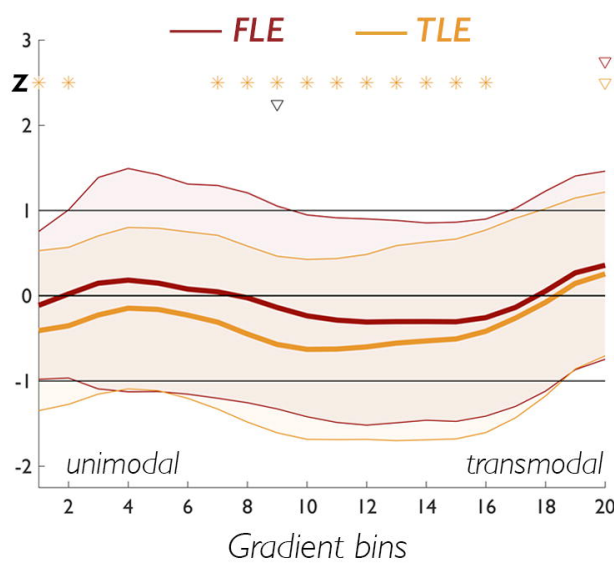

Task activity on gradient 
Figure 3 medRxiv preprint doi: https://doi.org/10.1101/2021.02.19.21251501; this version posted February 23, 2021. The copyright holder for this pee veview) is the author/funder, who has grented ad Rxiv a license to display the preprint in It is made available undere cC-BY-NC-ND 4.0 nternational license

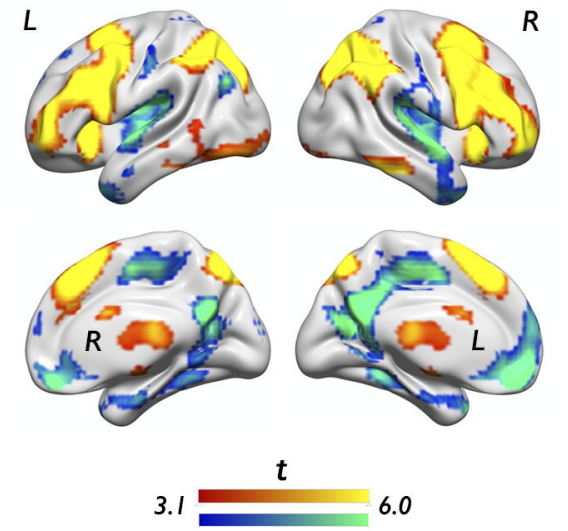

Voxel-based maps

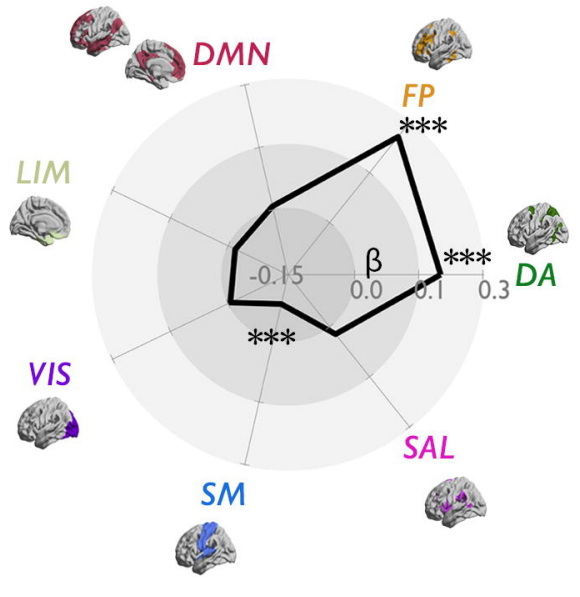

Task activity on systems

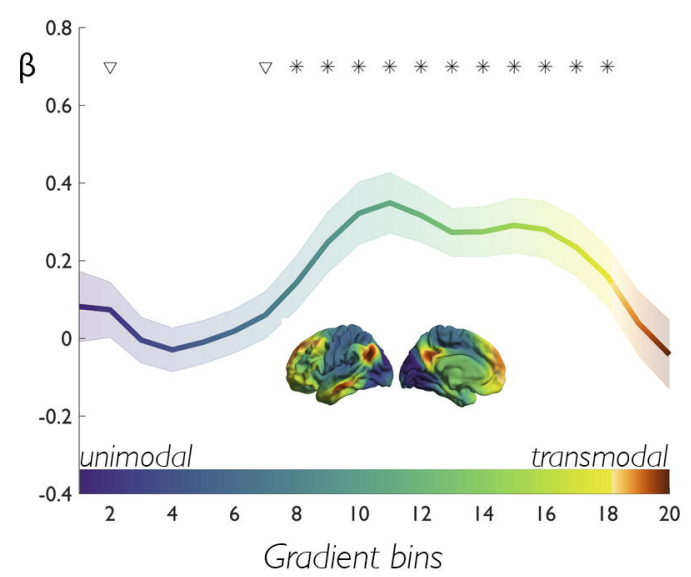

Task activity on gradient

\section{Visual working memory, I-O Back - task effects in CTR}

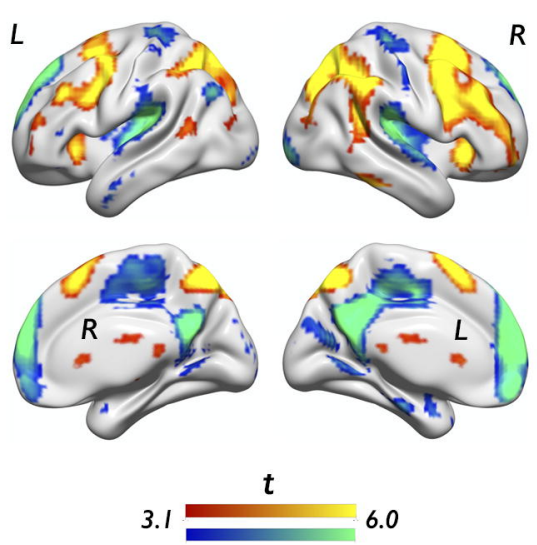

Voxel-based maps

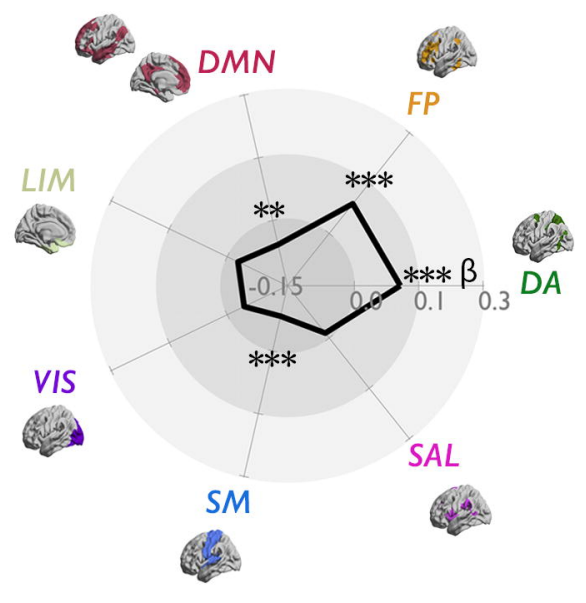

Task activity on systems

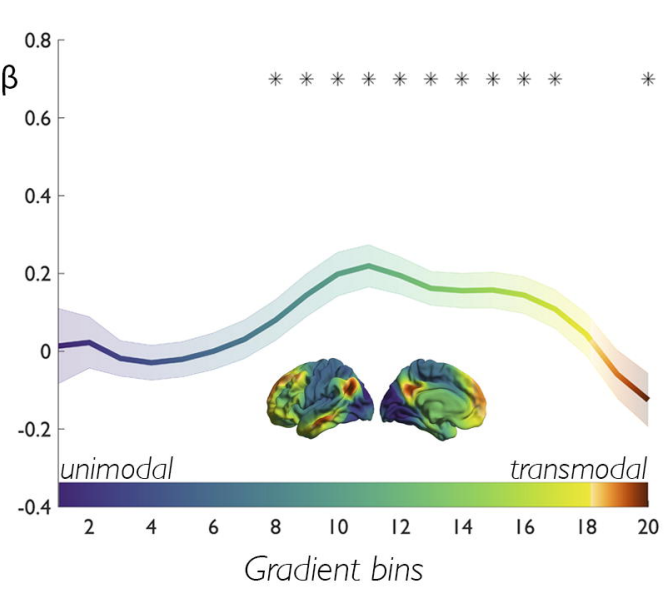

Task activity on gradient

\section{Visual working memory, 2-IBack - task effects in CTR}

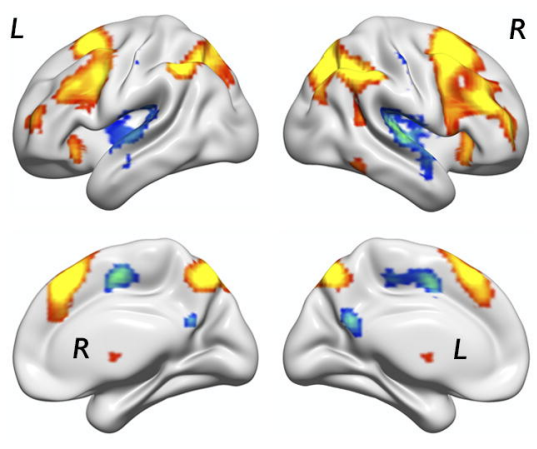

$3.1=6.0$

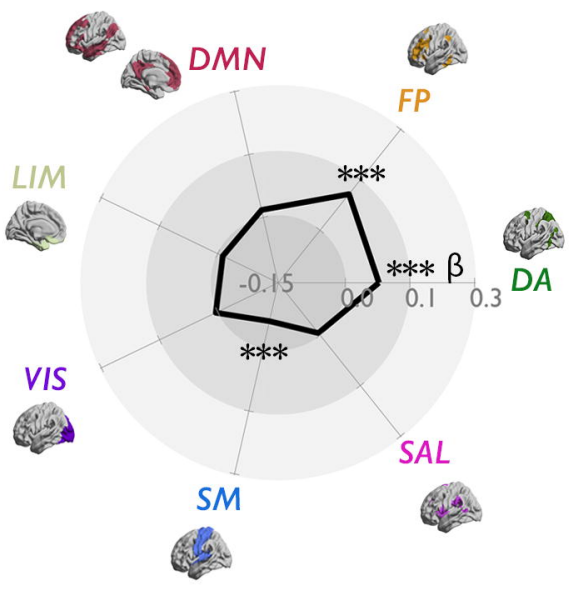

Task activity on systems

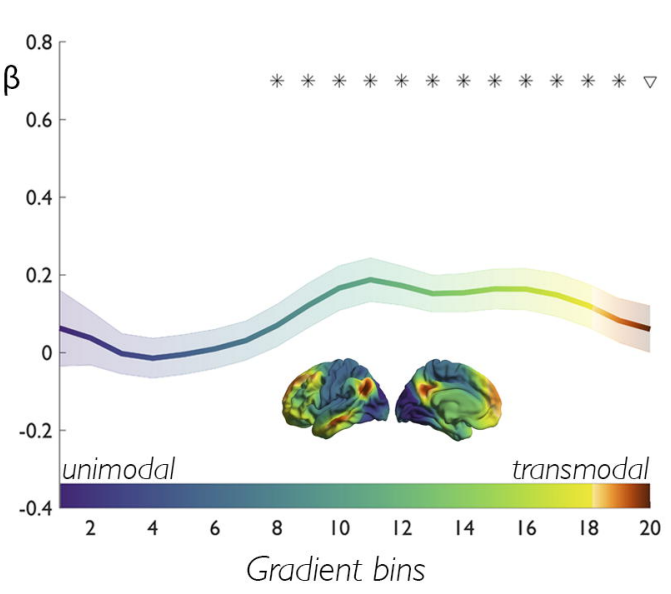

Task activity on gradient 


\section{Working Memory fMRI}

\section{Verbal working memory - group comparisons}

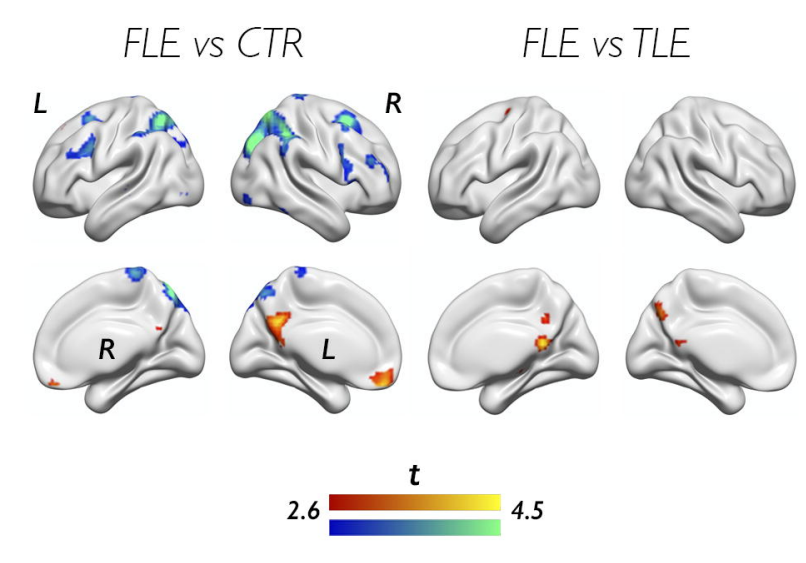

Voxel-based maps

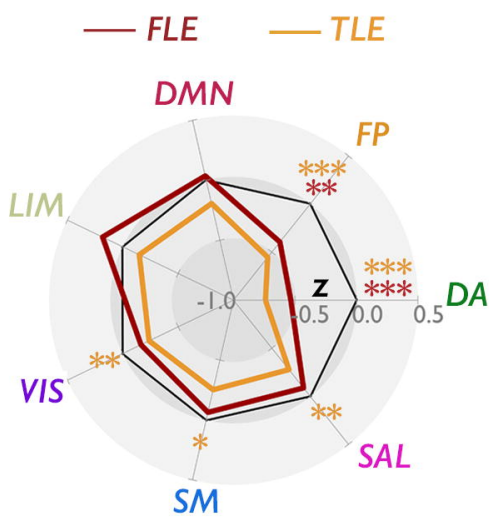

Task activity on systems

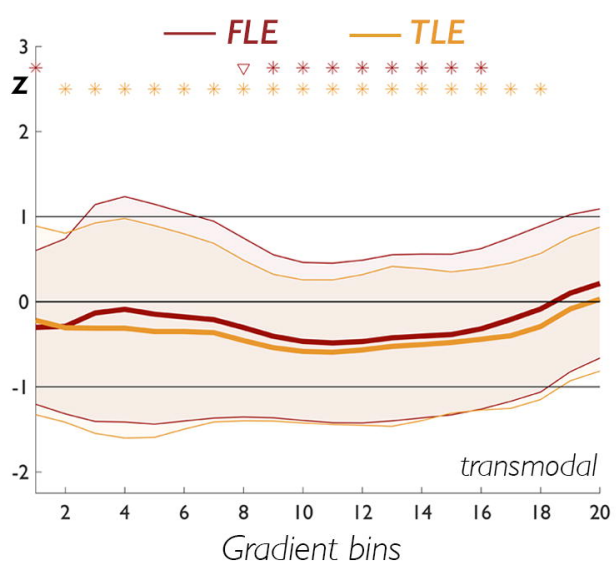

Task activity on gradient

\section{Visual working memory, I-0 Back - group comparisons}

FLE vs CTR FLE vsTLE
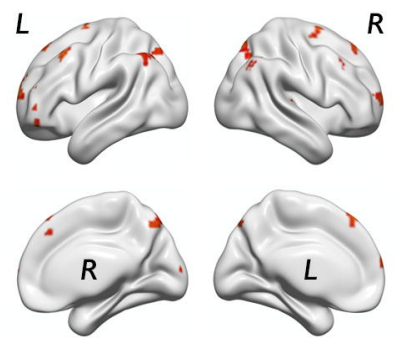
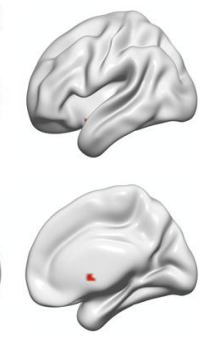

$t$

4.5

Voxel-based maps
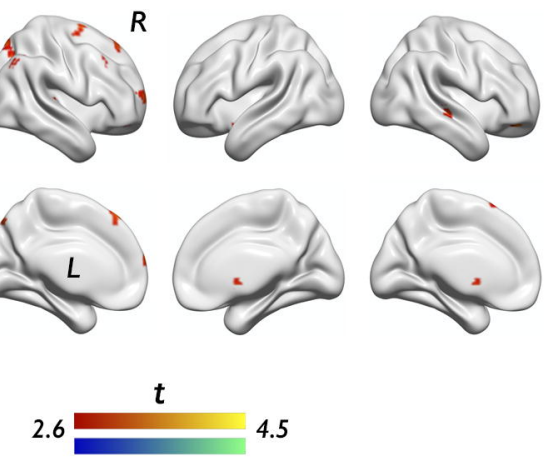

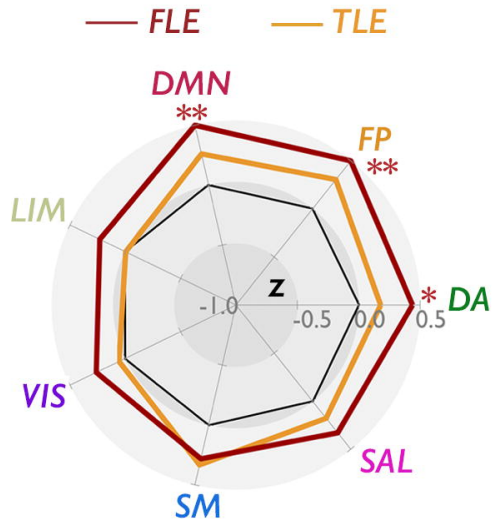

Task activity on systems

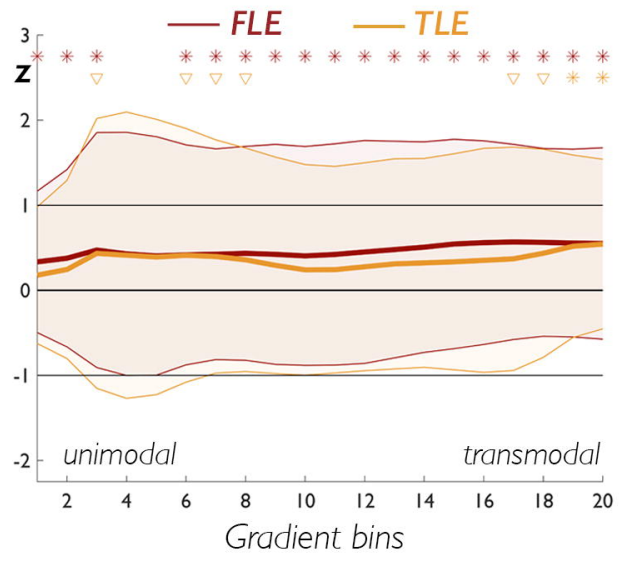

Task activity on gradient

\section{Visual working memory, 2-I Back - group comparisons}

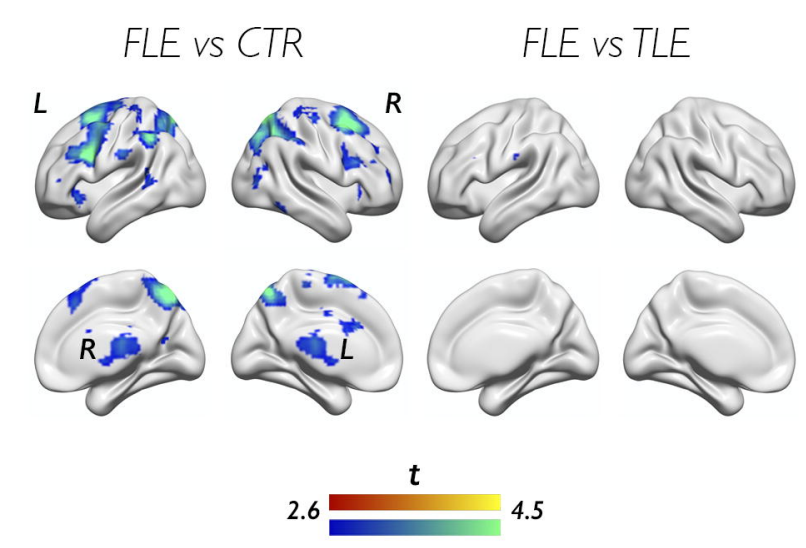

Voxel-based maps

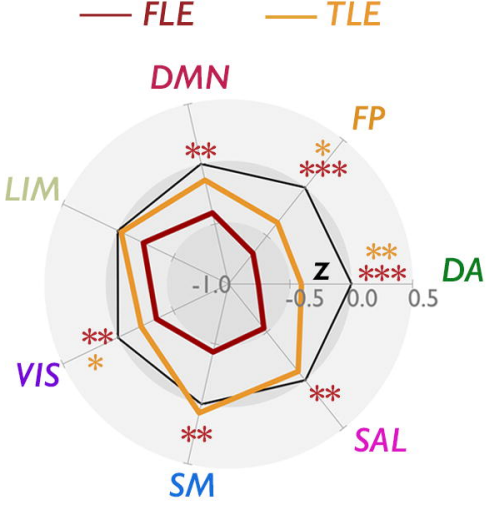

Task activity on systems

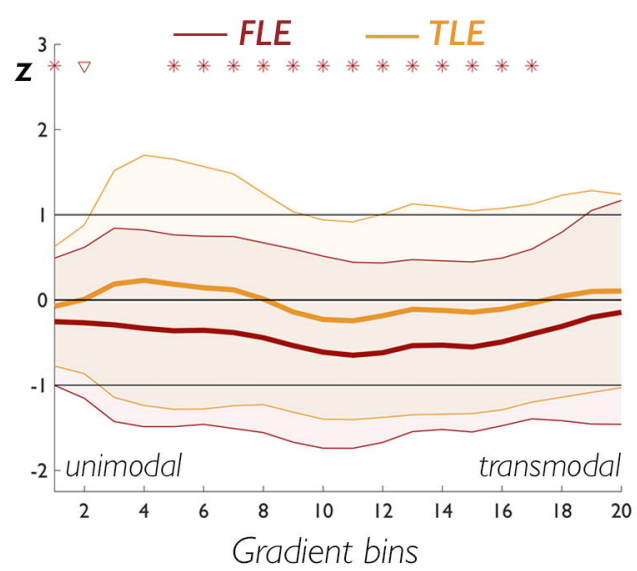

Task activity on gradient 


\section{Associations - imaging measures \& cognitive performance}

\section{Language fMRI}
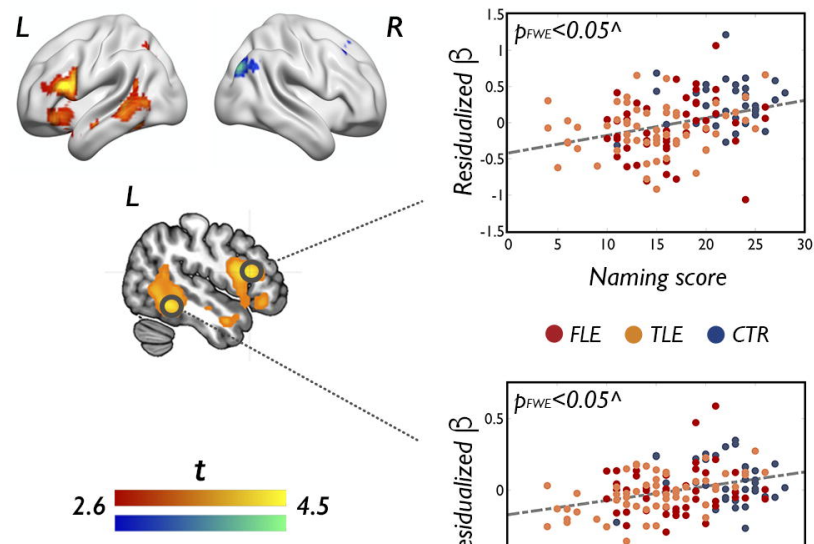

- fle tle ctr

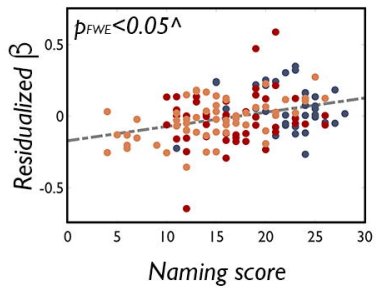

Verb generation activation \& naming

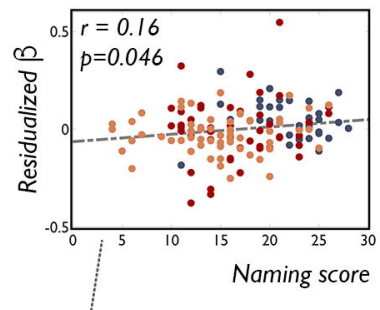

$D M N$

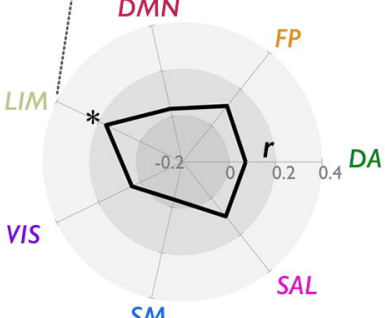

Verb generation activity on systems \& naming

Working memory fMRI
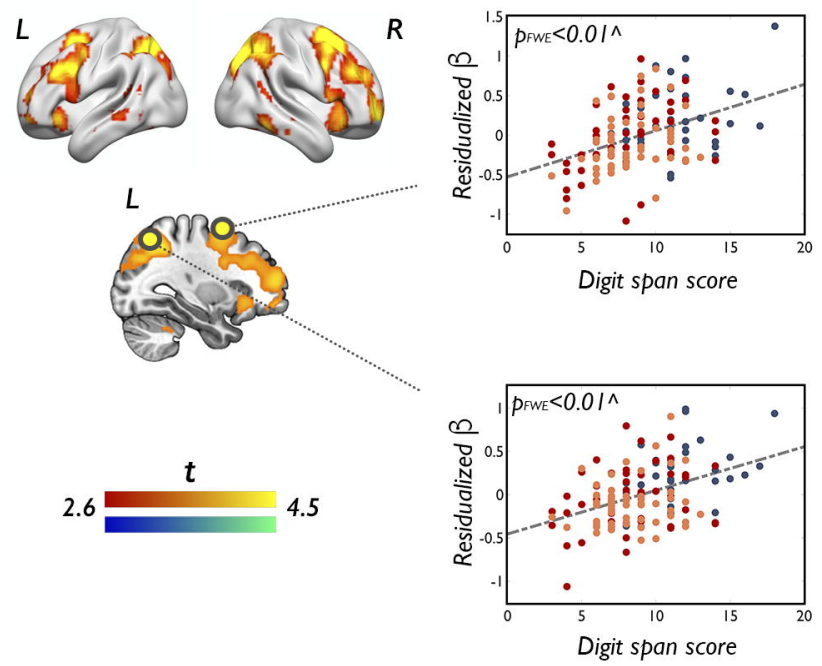

Verbal working memory activation \& digit span

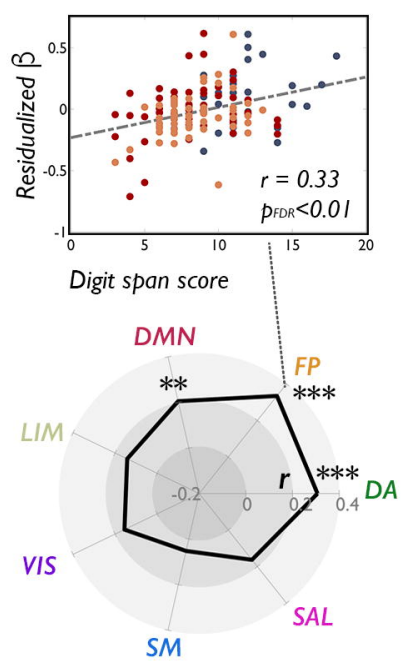

Verbal working memory activity on systems \& digit span
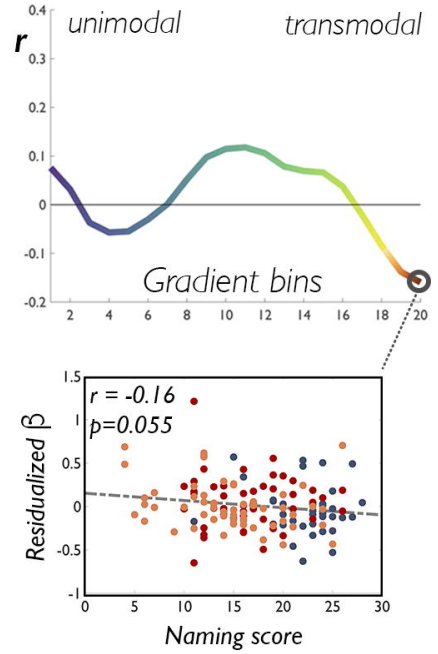

Verb generation activity on gradient \& naming

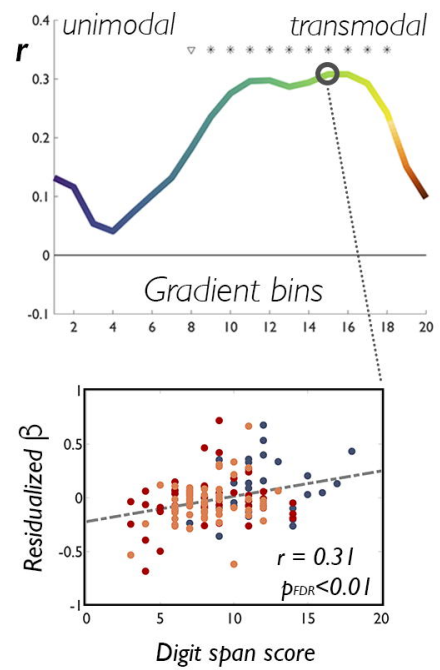

Verbal working memory activity on gradient $\&$ digit span 


\section{Language fMRI}

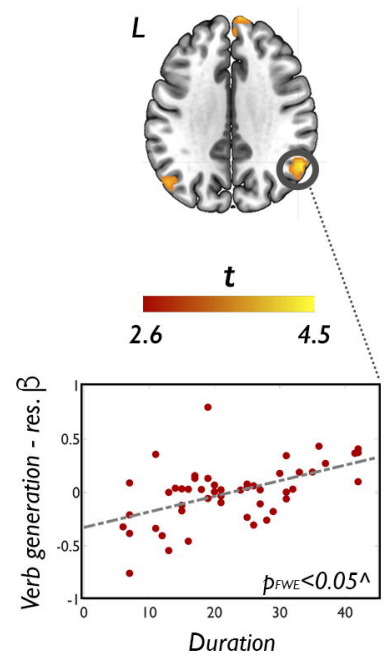

Verb generation \& duration voxel-based maps

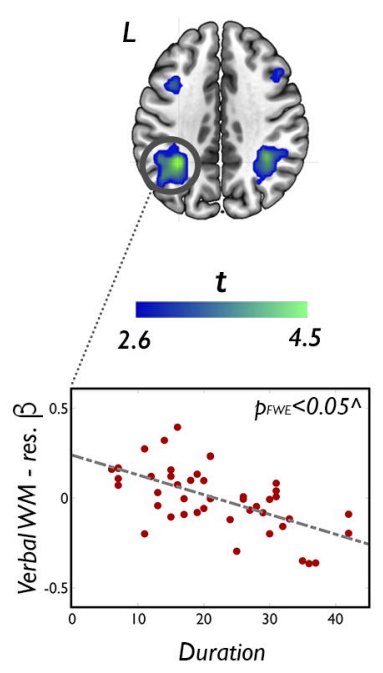

Verbal working memory \& duration voxel-based maps
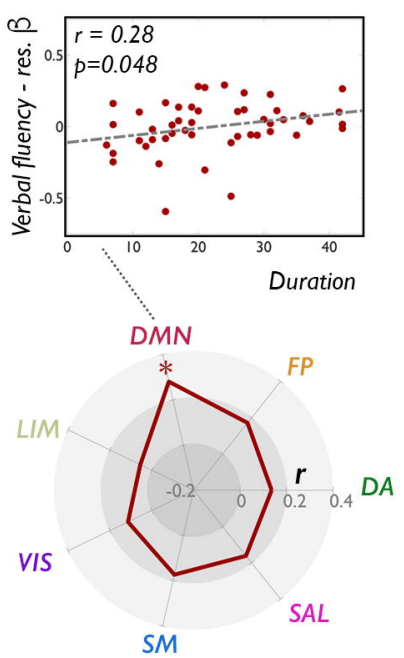

Verbal fluency \& duration systems

\section{Working Memory fMRI}

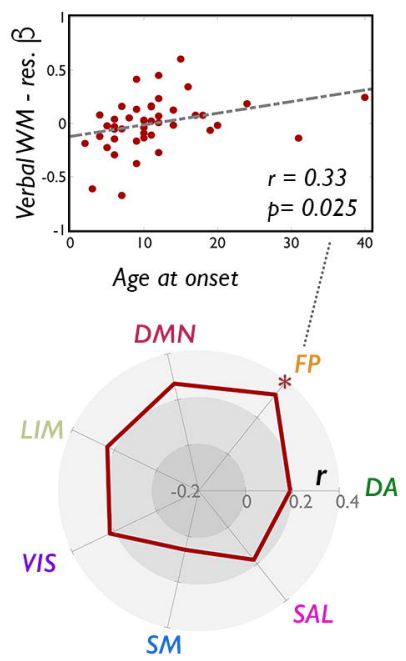

Verbal working memory \& age at onset, systems
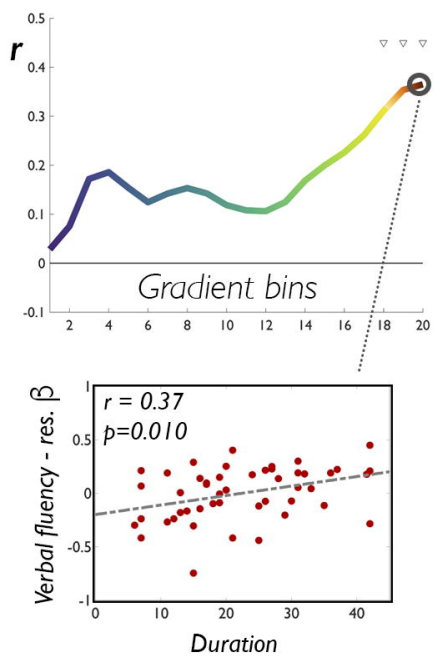

Verbal fluency \& duration gradient

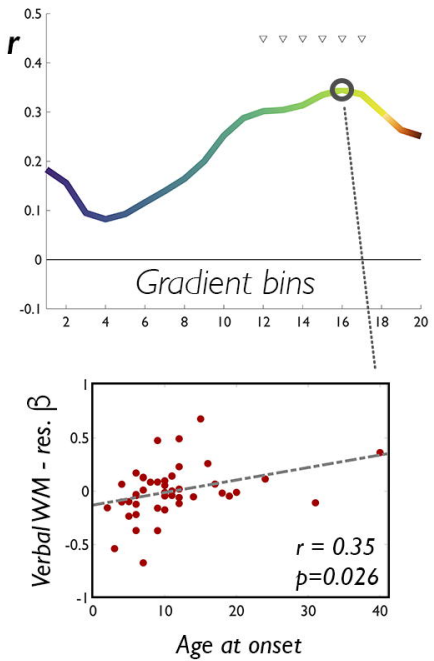

Verbal working memory \& age at onset, gradient 